\title{
TILTROTOR VIBRATION REDUCTION THROUGH HIGHER HARMONIC CONTROL
}

\author{
Mark W. Nixon \\ U.S. Army Vehicle Technology Center \\ NASA Langley Research Center \\ Hampton, Virginia \\ Raymond G. Kvaternik \\ NASA Langley Research Center \\ Hampton, Virginia \\ T. Ben Settle \\ Bell Helicopter Textron, Inc. \\ Fort Worth, Texas
}

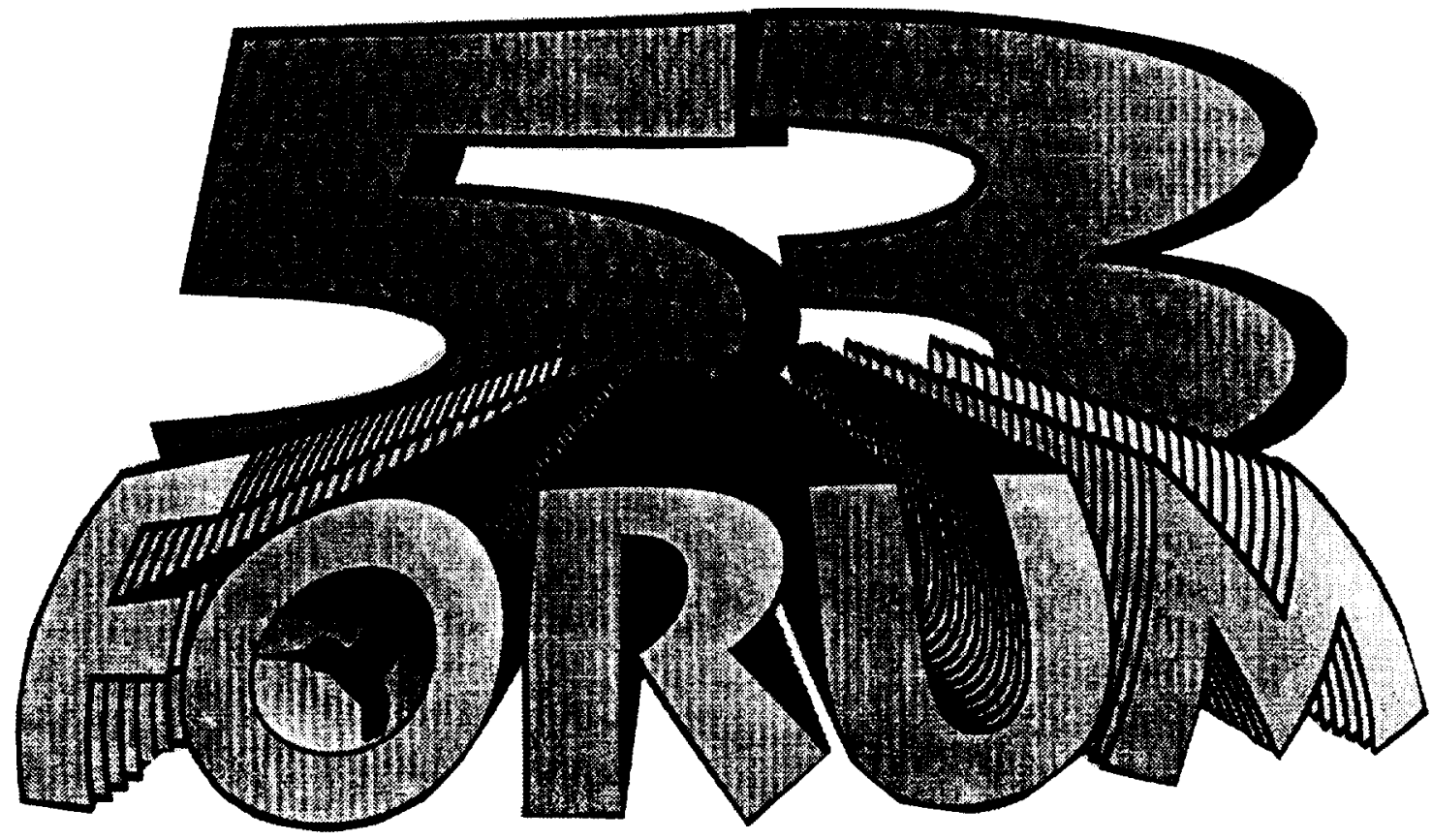

Presented at the American Helicopter Society 53rd Annual Forum, Virginia Beach, Virginia, April 29 - May 1, 1997 



\section{Tiltrotor Vibration Reduction Through Higher Harmonic Control}

\author{
Mark W. Nixon \\ Aerospace Engineer \\ ARL Vehicle Technology Center \\ Hampton, VA
}

\author{
Raymond G. Kvaternik \\ Senior Research Engineer \\ NASA Langley Research Center \\ Hampton, VA
}

\author{
T. Ben Settle \\ Research Projects Engineer \\ Bell Helicopter Textron, Inc. \\ Fort Worth, Texas
}

\begin{abstract}
The results of a joint NASA/Army/Bell Helicopter Textron wind-tunnel test to assess the potential of higher harmonic control (HHC) for reducing vibrations in tiltrotor aircraft operating in the airplane mode of flight, and to evaluate the effectiveness of a Belldeveloped HHC algorithm called MAVSS (Multipoint Adaptive Vibration Suppression System) are presented. The test was conducted in the Langley Transonic Dynamics Tunnel using an unpowered 1/5-scale semispan aeroelastic model of the V-22 which was modified to incorporate an HHC system employing both the rotor swashplate and the wing flaperon. The effectiveness of the swashplate and the flaperon acting either singly or in combination in reducing $1 \mathrm{P}$ and $3 \mathrm{P}$ wing vibrations over a wide range of tunnel airspeeds and rotor rotational speeds was demonstrated. The MAVSS algorithm was found to be robust to variations in tunnel airspeed and rotor speed, requiring only occasional on-line recalculations of the system transfer matrix. HHC had only a small (usually beneficial) effect on blade loads but increased pitch link loads by $25 \%$. No degradation in aeroelastic stability was noted for any of the conditions tested.
\end{abstract}

\section{NOTATION}

$B, C, T$

denotes wing beam, chord, and torsion response

CAA pylon conversion axis accelerometer, axial orientation

CAN pylon conversion axis accelerometer, normal orientation

$\begin{array}{ll}C G L & \begin{array}{l}\text { pylon c.g. accelerometer, } \\ \text { lateral orientation } \\ \text { load associated with HHC } \\ \text { performance index } \\ \text { resultant of loads associated with } \\ \text { performance index, HHC-on } \\ F\end{array} \\ F_{0} & \begin{array}{l}\text { resultant of loads associated with } \\ \text { performance index , HHC-off }\end{array} \\ J & \text { performance index (a scalar) } \\ K & \text { control matrix }\end{array}$

Presented at the American Helicopter Society 53rd Annual Forum, Virginia Beach, Virginia, April 29 - May 1, 1997.

\begin{tabular}{|c|c|}
\hline$K_{s}$ & number of samples in data \\
\hline$M^{s}$ & number of response points \\
\hline$n$ & denotes integer harmonic number \\
\hline$n P$ & denotes n-per-rev \\
\hline$N$ & number of control actuators \\
\hline$Q$ & $\begin{array}{l}\text { weighting matrix for control inputs } \\
\text { (diagonal) }\end{array}$ \\
\hline$R$ & $\begin{array}{l}\text { weighting matrix for responses } \\
\text { (diagonal) }\end{array}$ \\
\hline$T$ & $\begin{array}{l}\text { system transfer matrix relating changes } \\
\text { in response to changes in control }\end{array}$ \\
\hline$z$ & vector of vibratory responses \\
\hline$z_{i}$ & response feedback signal from ith gage \\
\hline$z_{n}$ & vector of target vibratory responses \\
\hline$Z_{i c} Z_{i s}$ & $\begin{array}{l}\text { HHC response vectors, cosine and sine } \\
\text { components, respectively }\end{array}$ \\
\hline$\alpha$ & caution parameter \\
\hline$\Delta$ & $\begin{array}{l}\text { denotes change in quantity which } \\
\text { follows }\end{array}$ \\
\hline$\theta$ & vector of $\mathrm{HHC}$ inputs \\
\hline$\theta_{m}$ & vector of allowable $\mathrm{HHC}$ inputs \\
\hline$\Theta_{j c}, \Theta_{j}$ & $\begin{array}{l}\text { HHC input vectors, cosine and sine } \\
\text { components, respectively }\end{array}$ \\
\hline$\psi$ & azimuth angle of reference blade, deg. \\
\hline$\Omega$ & rotor rotational speed \\
\hline
\end{tabular}

\section{INTRODUCTION}

Rotary-wing aircraft are prone to vibrations due to the intrinsic periodic nature of the airloads acting on the rotor blades. Tiltrotor aircraft operating in the airplane mode of flight are inherently less susceptible to vibrations than helicopters because the airflow through their rotors is predominantly axial rather than inclined. However, airframe vibration levels in tiltrotor aircraft are still typically greater than those in conventional propeller-driven fixed-wing aircraft. There are two principal sources of rotor-induced airframe vibration in a tiltrotor operating in the airplane mode of flight: (1) the aerodynamic interference between the rotor blades and the wing; and (2) the wake of the rotor impinging on the empennage. The circulation associated with a lifting wing and the streamline curvature induced by a finite-thickness wing create an azimuthally unsym- 
metric flow field through the rotor disc which results in oscillatory blade loads that are transmitted to the hub and down the mast into the airframe (pylon, wing, fuselage) as vibratory forces and moments at frequencies which are integer multiples of the blade passage frequency. The shed rotor wake also excites the airframe at the blade passage frequency. While these effects are present in conventional propellerdriven aircraft, they are more significant in tiltrotors because of the larger diameter of proprotors as compared to propellers. One approach to reducing proprotor-induced airframe vibrations is to actively control the vibrations at their source (the rotor) by introducing higher harmonic collective and cyclic blade pitch using the fixed-system swashplate to modify the blade aerodynamic loading in a manner which eliminates or at least reduces substantially the resultant rotor loads entering the airframe at the hub. The use of the rotor swashplate to actively control vibration in this way is generally referred to as higher harmonic control (HHC). However, it is clear that HHC systems for vibration reduction can also utilize airframe control surfaces such as flaps, ailerons, elevators, and rudders, airframe-mounted devices such as seismic masses and force actuators, and blademounted devices such as actively-controlled pitch links and control surfaces.

The use of active controls to reduce vibrations in helicopters has been studied both analytically and experimentally for many years (see, for example, refs. 1-26). Several different approaches to mechanically introducing the necessary higher harmonic control inputs have been investigated including the swashplate (refs. 1-16), blade-mounted devices (refs. 17-22), and force actuators mounted in the fuselage (refs. 23-26). Various types of control algorithms, both deterministic and stochastic, were also evaluated as part of these studies. HHC methods based on using an activelycontrolled swashplate have the longest research history and have received the most attention. Concise summaries of the work dealing with this approach may be found in references 16,27 , and 28 . The crucial role played by the vibration control algorithm in any practical implementation of $\mathrm{HHC}$ is well recognized and considerable attention has also been devoted to this aspect of helicopter HHC systems (see, for example, refs. 5, 6, 9, and 14). Based on the results of these studies, higher harmonic control using an actively-controlled swashplate has been judged to be one of the most effective vibration control techniques applicable to helicopters. Some of the most significant findings associated with the HHC studies reported in the literature are: (1) The major oscillatory rotor loads transmitted into the nonrotating system can be effectively eliminated by oscillating the swashplate at a single harmonic of the rotor rotational speed; (2) Simultaneous reduction of several components of the vibratory hub loads is possible due to superposition of the effects of the individual harmonic pitch oscillations: (3) HHC has a negligible effect on rotor performance: (4) HHC has only a small effect on blade loads: (5) Pitch link loads can be significantly increased: and (6) An adaptive HHC system requires a
Kalman Filter to identify the helicopter transfer function.

Tiltrotor aircraft operate in both the helicopter and airplane modes of flight. Because tiltrotors are designed to spend most of their flight time in the airplane mode, primary interest for this type of rotorcraft is on reducing airframe vibrations when operating in the airplane mode of flight. While much of the $\mathrm{HHC}$ research conducted for helicopters is probably directly applicable to tiltrotors operating in the helicopter mode of flight, it is not clear how much of that work (if any) is directly applicable to tiltrotor aircraft operating in the airplane mode of flight. There is some work reported in the literature which deals with the active control of flapping and gust response of tiltrotors in airplane mode (see, for example, refs. 2933 ), but there is a dearth of information which deals specifically with the problem of vibration reduction. Because both the aerodynamic environment and aeromechanical behavior of tiltrotors operating in the airplane mode are significantly different from those of helicopters, the design requirements for the implementation of an effective HHC system could be much different. For example, some results (e.g., ref. 16) indicate that the oscillatory amplitudes required to suppress vibration are strongly dependent on the dynamics of the rotor system. Current tiltrotors use gimbaled, stiff-inplane rotor systems which exhibit significantly different dynamic behavior than the hingeless and articulated rotor systems which have been used in most previous investigations of HHC. The aerodynamics generating the blade periodic airloads which result in vibration at the hub are also quite different. The airloads acting on the blades of a helicopter rotor in forward flight are highly periodic due to both the inclination of the airflow through the rotor disc and the influence of the wake on the flow field near the rotor. Because the airflow through the rotor of a tiltrotor operating in the airplane mode is primarily axial there are no first-order periodicities associated with the forward flight velocity as there are for a helicopter. Tiltrotor hub vibrations arise from the periodic airloads resulting from perturbations to the uniform flow through the rotor due to aerodynamic interactions between the rotor and the wing as discussed earlier; the rotor wake has little effect on the blade airloads. Another important difference between a tiltrotor and a helicopter is rotor disc loading. The disc loading of a tiltrotor in an airplane mode is an order-ofmagnitude smaller than that of a helicopter of comparable gross weight. Since typical HHC systems produce a reduction in vibrations by a redistribution of the aerodynamic loads around the azimuth of the rotor disc, there is a question of how effective an HHC system can be for a rotor which has a low disc loading.

Most recent analytical studies, wind-tunnel tests, and flight tests of HHC-based vibration control systems have employed a Kalman filter for on-line identification of the system parameters required by the HHC algorithm. The basic premise has been that a real-time Kalman filter, or its equivalent, is required to accurately identify the system transfer matrix. 
Because of the "cleaner" aerodynamic environment associated with a tiltrotor when operating as an airplane, the computational requirements for an effective tiltrotor-based $\mathrm{HHC}$ algorithm may be much reduced. In this regard, Bell Helicopter Textron, Inc. (BHTI) developed a vibration suppression algorithm called MAVSS (Multipoint Adaptive Vibration Suppression System) and conducted a series of dynamic tests which indicated that a simpler control algorithm could probably be used. A successful windtunnel demonstration of the effectiveness of a MAVSScontrolled active flaperon for reducing airframe vibrations was subsequently carried out (Ref. 34). However, it was recognized that further testing of MAVSS was required to validate the algorithm for use as an HHC system in tiltrotor applications.

The purpose of this paper is to summarize the results of a joint NASA/Army/BHTI investigation which was conducted in the Langley Transonic Dynamics Tunnel to assess the potential of HHC for reducing vibrations in tiltrotor aircraft operating in the airplane mode of flight, and to further evaluate the effectiveness of the MAVSS control algorithm. The wind-tunnel study employed a 1/5-scale semispan aeroelastic model of the V-22 which was modified to incorporate an HHC system consisting of the rotor swashplate and the wing control surfaces (flap and aileron) acting together as a single control surface. For convenience, the flap/aileron combination is called a flaperon in this paper. Three high-frequency servo-controlled hydraulic actuators were employed to control the swashplate and a fourth actuator was used to control the flaperon. The required $\mathrm{HHC}$ swashplate commands as determined by the MAVSS algorithm were summed with the pilot trim commands to produce the desired oscillatory swashplate actuation about a trim state. The effectiveness of the rotor swashplate and the wing flaperon in reducing vibrations was investigated both singly and in combination over a wide range of tunnel airspeeds and rotor rotational speeds. The robustness of the vibration control system to variations in tunnel airspeed and rotor speed, both separately and in combination, was studied. The effect of HHC on blade loads, pitch link loads, and aeroelastic stability was also assessed.

\section{EXPERIMENTAL SETUP}

\section{Model}

The model used in the investigation is a modified version of a 1/5-scale semispan aeroelastic model of the V-22 tiltrotor which was used to support the preliminary and full-scale design phases of the V-22 aircraft (Ref. 35). Upon completion of that series of tests, the Navy transferred the model to NASA Langley under a loan agreement to be used as the experimental testbed of a tiltrotor aeroelastic and structural dynamics research program which was initiated at Langley in 1994. The tiltrotor testbed has been desig-

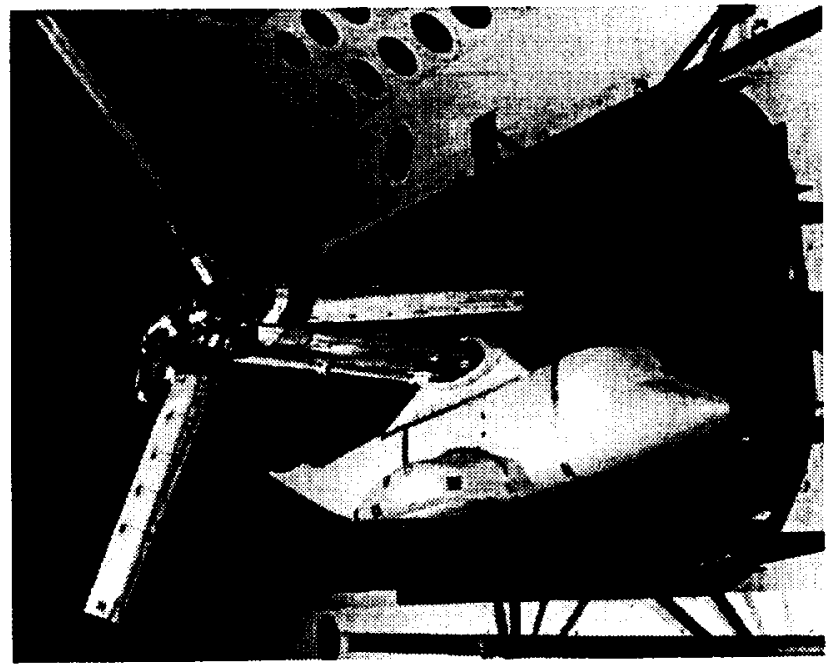

Figurel. Model in Langley Transonic Dynamics Tunnel

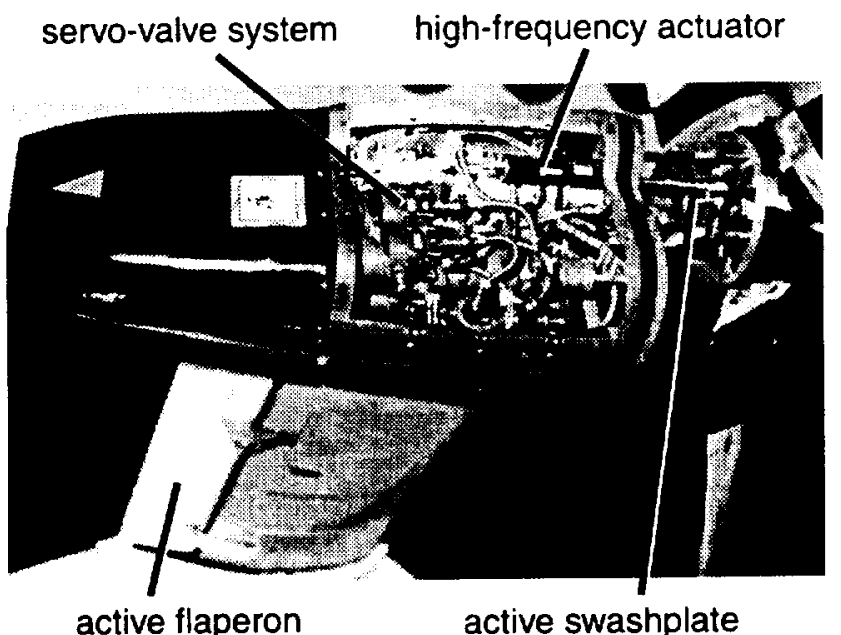

Figure 2. Hardware components of the higher harmonic control system.

nated the Wing and Rotor Aeroelastic Testing System (WRATS).The Wing and Rotor Aeroelastic Testing System (WRATS) tiltrotor model as installed in the Langley Transonic Dynamics Tunnel for this study is shown in Figure 1. Modifications to the baseline model required for the active controls testing included the replacement of the electric control actuators with high-frequency hydraulic servo-actuators to drive the swashplate and a new servo-controlled wing flaperon. Some of these new components are indicated in Figure 2. The model also incorporated a new, elasticallytailored, graphite-epoxy wing spar. This spar was used in an earlier aeroelastic stability investigation (Ref. 36) unrelated to the present study and left on the model for convenience. 


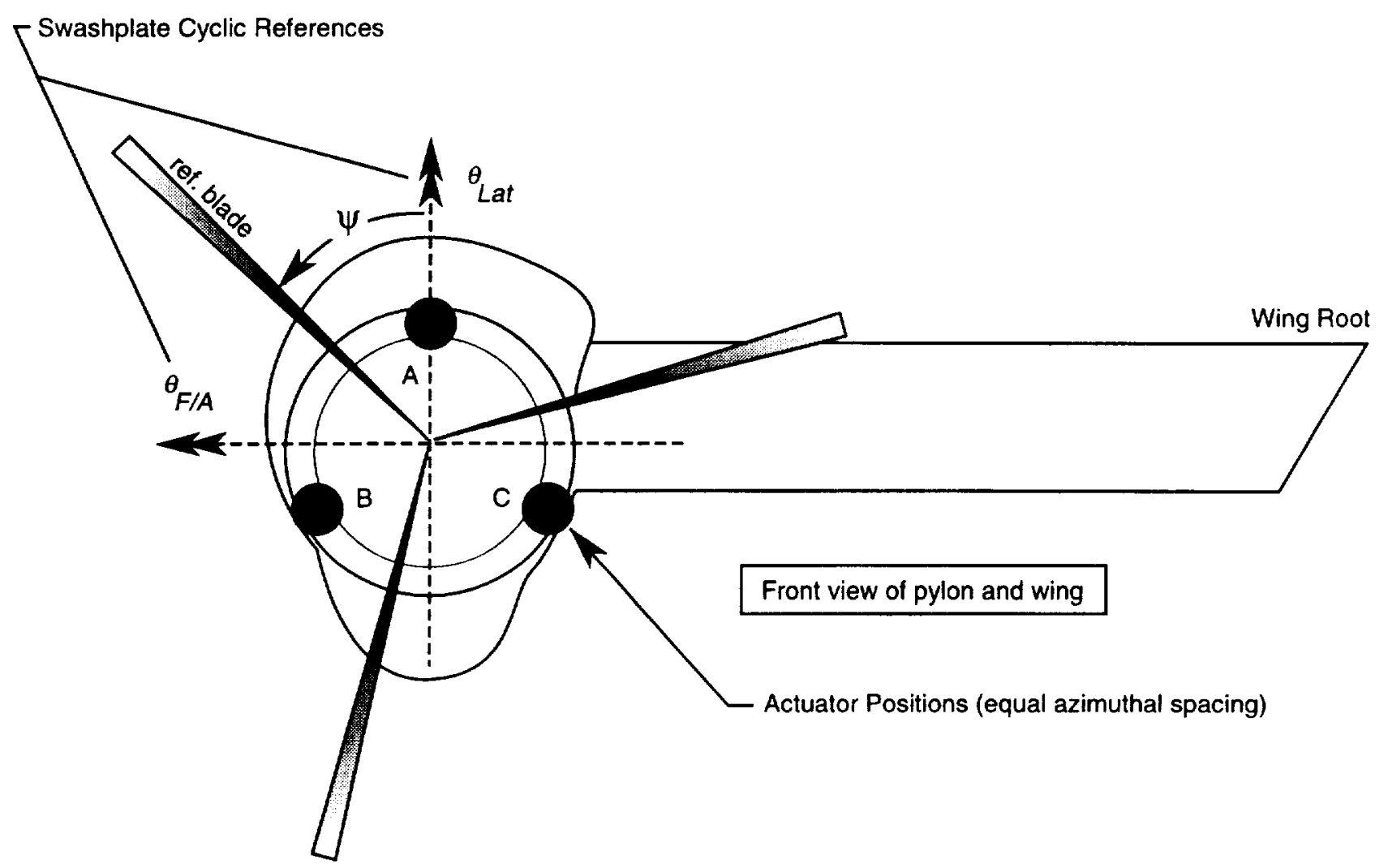

Figure 3. Actuator positions and swashplate cyclic reference.

The model has a length scale factor of $1 / 5$ and was designed to maintain full-scale values of the Froude, Lock, and Strouhal numbers when operated in air (Ref. 35). The wing and rotor are dynamically and aeroelastically scaled; the pylon is only dynamically scaled. The fuselage is rigid and only maintains the scaled external aerodynamic shape. The model is attached to a support structure which is effectively rigid, its lowest frequency being well above any important elastic mode frequency of the model. Simulation of the distributed wing beamwise, chordwise, and torsional stiffness is provided by means of a hollow, elastically-tailored, composite spar having chordwise flanges. The 4.6-foot spar, which lies along the calculated elastic axis of the wing, has segmented, nonstructural, aluminum aerodynamic fairings which provide the spanwise distribution of airfoil contour. To provide surface continuity over the wing lifting surface, the gap between the segments at the surfaces is filled by strips of foam rubber. The wing-tip-mounted pylon contains the transmission and gearbox components for the rotor drive system, the lower part of the mast, and the swashplate control system. Because these internal components can be treated as rigid, the pylon was scaled dynamically so as to preserve its overall mass and inertia properties. The pylon is attached to the wing tip by means of a "racetrack" spring assembly which simulates the combined stiffness of the full-scale conversion actuator and downstop-lock mechanism.

The 3-bladed, 7.6-foot diameter rotor has a gimbaled hub which is connected to the mast by a constant velocity joint ( 2 coincident universal joints). The rotor yoke has 2.5 degrees of built-in precone and is flexible to allow the blade coning angle to adjust under aerodynamic and centrifugal loading. The blades have a nonlinear distribution of built-in twist with an overall root-to-tip twist of 47.5 degrees (leading edge down).

A large plywood panel through the vertical plane of symmetry of the model and attached to a support structure consisting of a spider-like arrangement of steel tubes which was employed to seal the open back side of the semi-fuselage and to serve as a reflection plane. The structure also provided the offset needed to position the rotor axis near the centerline of the wind tunnel test section. 


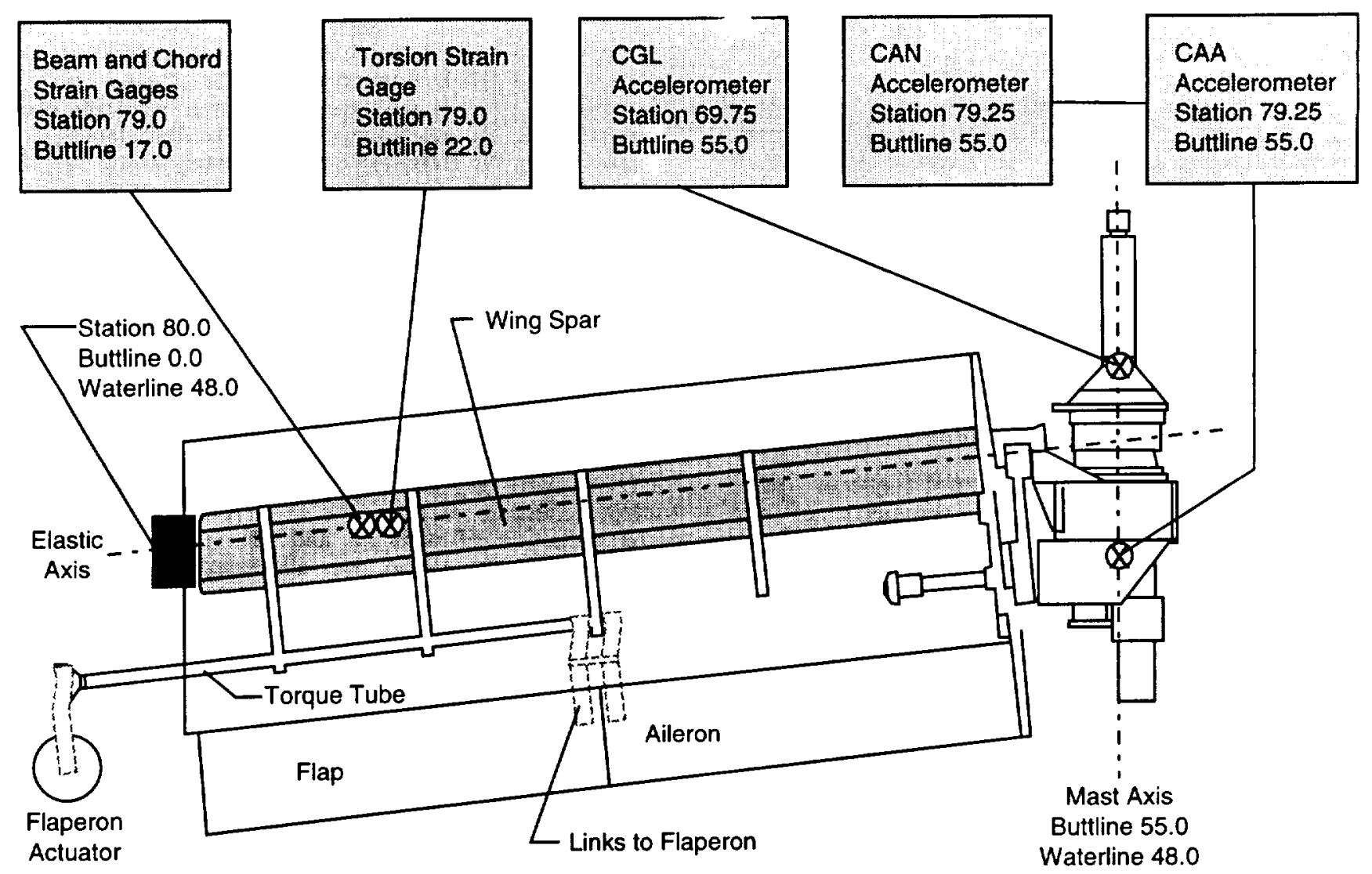

Top view of wing and pylon

Figure 4. Wing planform geometry and location of gages used for response feedback.

The fundamental natural frequencies of the model with the pylon locked to the downstop, the rotor on, and flapping locked out, are summarized in Table $I$.

Typical frequencies of the rotor system in cruise flight ( $V=100$ knots, $\Omega=742 \mathrm{Rpm}$ ) are gimbal flapping at $.85 \mathrm{P}$, first cyclic lag at $1.5 \mathrm{P}$, and collective flap (coning mode) at about 1.3P. The fundamental cyclic flapping is coupled with the gimbal motion and the

\section{Table I - System Natural Frequencies*}

\begin{tabular}{lc}
\hline \multicolumn{1}{c}{ Mode } & Frequency, \\
& $\mathrm{Hz}$ \\
\hline Wing Beam Bending & 4.83 \\
Wing Torsion & 9.00 \\
Wing Chord Bending & 11.09 \\
Pylon Yaw (2nd Wing Chord) & 19.5 \\
Ist Elastic Blade Flap & 7.2 \\
1 st Elastic Blade Lag & 12.5 \\
1 st Elastic Blade Torsion & 109.9 \\
\hline
\end{tabular}

* Flapping locked out and rotor not turning. collective lag is coupled with the engine drive system dynamics. The present test was run without the drive system connected so the collective lag mode has zero frequency.

\section{Active Swashplate and Flaperon Hardware}

A total of four high-frequency hydraulic servo-actuators were used in the control system, one to drive the flaperon and three to drive the swashplate. The swashplate actuators were arranged in a 'milkstool' configuration around the nonrotating part of the swashplate as indicated in Figure 3. These actuators were used to input the usual steady pilot commands as well as the higher harmonic swashplate excitations called for by the active control algorithm. These servoactuators were made up of four Oildyne 3/4" hydraulic cylinders with Moog Series 32 servo-valves which provided a bandwidth in excess of $50 \mathrm{~Hz}$ at $3000 \mathrm{psi}$ supply pressure. The swashplate servo-valves were located inside the pylon near their corresponding actuators (see Figure 2). The flaperon actuator and its servo-valve were located inside the fuselage fairing at the root of the wing. Harmonic swashplate actuation 
was limited to \pm 2 degrees for each of the three control angles.

The new flaperon needed for active controls testing was designed to withstand the dynamic loads associated with oscillating the flaperon up to \pm 6 degrees at $50 \mathrm{Hertz}$. The flap and aileron which comprise the flaperon are identical, each having a span half the length of the wing and a five-inch chord. The flaperon is attached to a torque tube which is positioned along the 3/4-chord of the wing and supported by hanger bearings (Figure 4). Harmonic excitations of the flaperon were limited to \pm 3 degrees for most of the test.

\section{Feedback Signals and Instrumentation}

Feedback signals for the control system were developed from the measured responses of the pylon/wing system. The suite of candidate responses included wing root strain gages (beam, chord, and torsion) and three pylon accelerations. Analog response signals of interest were digitized and a realtime harmonic analysis was performed to extract the response at the harmonic frequency (or frequencies) of interest. The cosine and sine components of these harmonics were then input to the MAVSS HHC algorithm which calculated and updated the actuator signals required to minimize the vibration.

Locations of important instrumentation used for response feedback to the control system are illustrated in Figure 4. Wing bending and torsion moments are calibrated to standard strain-gage bridges located near the wing root. The beam and chord strain gages are located 17.0 inches out from the root and the torsion strain gages are located 23.0 inches out from the root. The three pylon acceleration responses used in this study are denoted in Figure 4 as ' $C G L$ ' (center-ofgravity-lateral acceleration), ' $C A N$ ' (conversion axisnormal acceleration), and ' $C A A$ ' (conversion axis-axial acceleration), where lateral motion is in a direction perpendicular to the mast axis in the plane of the wing and is positive starboard, normal motion is perpendicular to the wing plane and is positive up, and axial motion is along the mast axis and is positive aft. The wing bending and torsion gages were the sensors selected most often for feedback. A number of other measurements were monitored and recorded either to trim the rotor or for flight safety including: gimbal flapping, the downstop spring load, pitch-link load (one pitch link instrumented), and blade flapwise and chordwise bending at five spanwise locations (one blade instrumented). Blade torsion was not measured.

\section{Control System Architecture}

A schematic diagram of the control system for reducing $3 P$ vibrations in the airframe is shown in Figure 5. Flapping response of the rotor is displayed to the pilot as IP lateral and longitudinal flapping of the rotor tippath-plane. The pilot trims the model by setting both the collective pitch (to maintain the desired rotor speed on the windmilling rotor) and the cyclic pitch (to maintain zero flapping with respect to the mast). A mixer in the pilot control console calculates the commands to be sent to the individual actuators based on the pilot stick commands. The steady (DC) swashplate actuator commands required for trim are summed with the oscillatory $3 \mathrm{P}$ actuator commands as calculated by the HHC system. The total analog signal for each actuator is composed of $3 \mathrm{P}$ sine and cosine components having a constant (DC) offset. The sine and cosine components are with respect to the azimuth position of a reference blade such that the cosine component is a maximum when the reference blade is pointing up ( $\psi=0$ degrees) and the sine component is a maximum when the reference blade is pointing outboard ( $\psi=90$ degrees).

While the discussion above has specifically addressed reduction of $3 \mathrm{P}$ vibrations, the control system can accommodate any fixed-system vibration which is an integer multiple of the rotor speed $(1 \mathrm{P}, 2 \mathrm{P}, 4 \mathrm{P}, \ldots)$. The reduction of both $1 P$ and $3 P$ vibrations, either singly or in combination, was addressed in the present study.

\section{HIGHER HARMONIC ACTIVE VIBRATION CONTROL ALGORITHM}

The higher harmonic active vibration control algorithm employed in this study is implemented in a BHTI proprietary software system called the Multipoint Adaptive Vibration Suppression System (MAVSS). MAVSS is designed to minimize rotorcraft vibrations occurring at integer multiples of the rotor speed. For a three-bladed rotor system, the largest vibratory forces acting on the airframe occur at a frequency of threeper-rev (3P). The MAVSS algorithm assumes that changes in the aircraft responses are linearly related to changes in control inputs through a system transfer matrix which represents a locally-linearized model of the measured aircraft dynamics. Should the algorithm detect that its (current) linearized model is no longer providing an adequate representation of the system dynamics, MAVSS re-identifies the transfer matrix on line. MAVSS operates in the rotor frequency domain in near real time. All data acquisition and commands are triggered by rotor position and thus MAVSS can remain synchronized with the rotor rotational speed, even if the rotor speed varies. Commands for the current rotor revolution are computed based on the measurements made on the last rotor revolution and its linearized model of the measured aircraft dynamics. The deterministic controller on which MAVSS is based is obtained by minimizing a scalar performance index which includes the harmonic vibratory responses to be reduced, the HHC inputs necessary to effect the reduction, and the transfer matrix describing the dynamics of the system. Since both measured vibrations and actuator commands are included in the performance index, the system always tries to minimize both the measured vibrations and the work done by the actuators. 


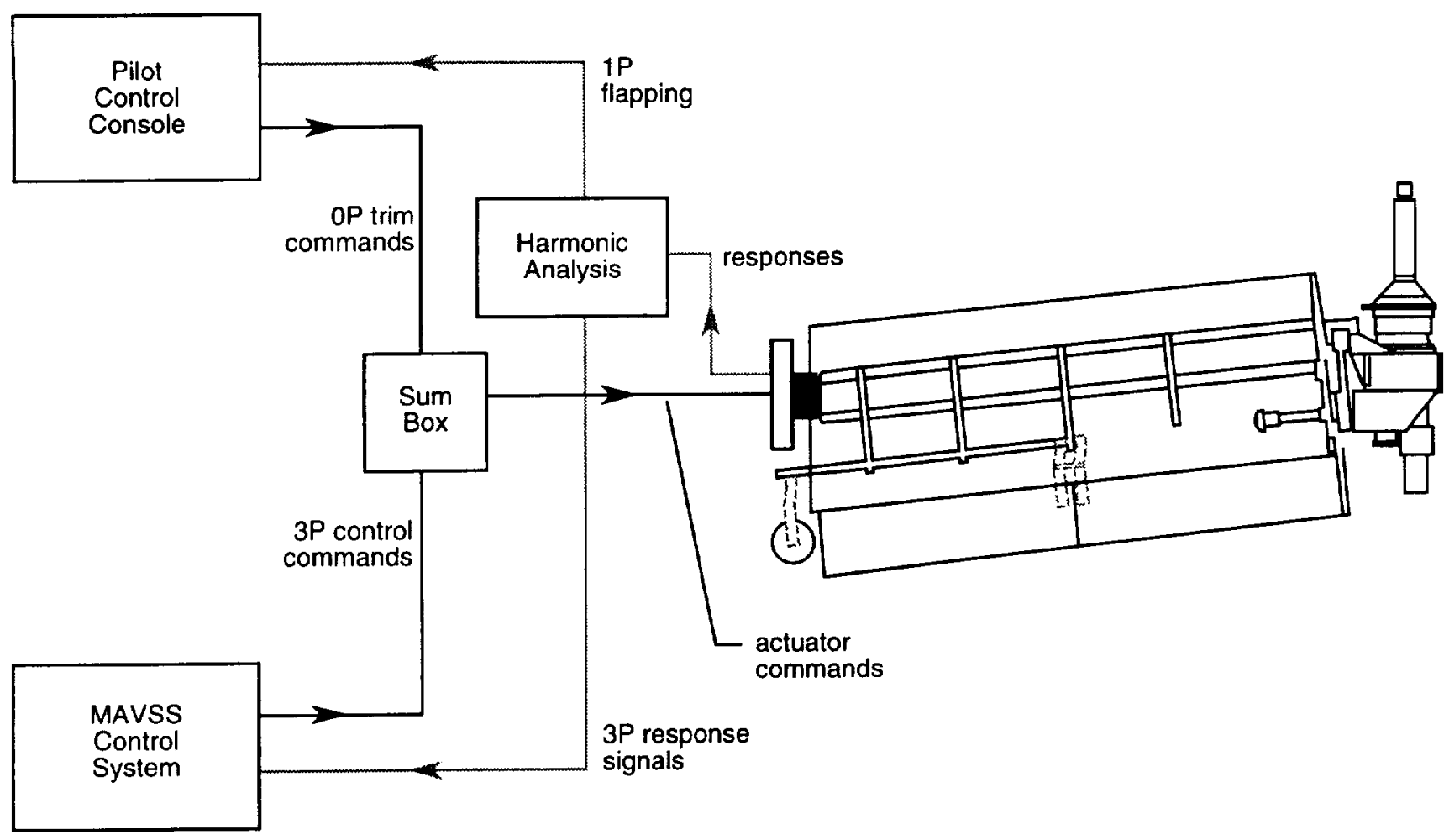

Figure 5. Schematic of active vibration control system arrangement.

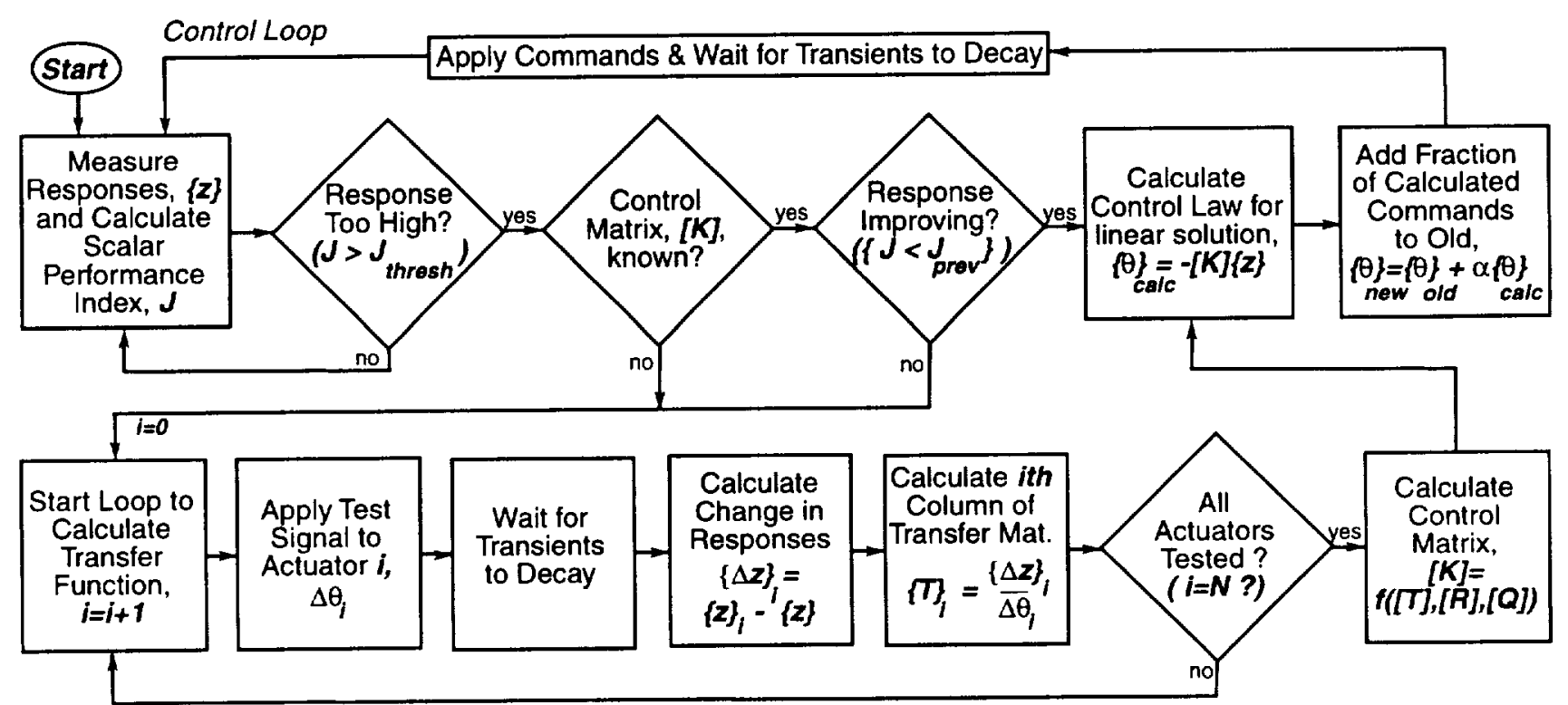

Identification Loop

Figure 6. Major computational blocks in MAVSS active vibration control algorithm 
A simplified flowchart which indicates the major computational blocks in MAVSS is shown in Figure 6. To start the process, the system responses at the harmonics of interest (e.g., 3P) are measured and the performance index is evaluated and compared to the threshold (target) value of the index. The initial value of the index should be well above the threshold value because no control has yet been applied. As MAVSS has no prior knowledge of the aircraft dynamics when it is first started, the system transfer matrix must be identified. MAVSS calculates this matrix by applying a known signal at the harmonic of interest to each of its control actuators in turn and then normalizing the resulting change in system vibrations by the applied signal. To account for the possibility of system nonlinearities, only a fraction of the calculated control change is added to the existing control and then applied to the actuators. The performance index is then recalculated using the new vibratory responses and compared to both its previous value and the threshold value. If the new index is smaller than the previous value but is still larger than the threshold value then a new set of control commands is calculated. Continuing in this manner, the index is driven down incrementally to just below its threshold value. Once the measured vibrations are below the threshold value, MAVSS simply maintains the latest set of commands and monitors the aircraft responses. Should the flight condition or forcing function change and the measured responses exceed the threshold, MAVSS uses the latest measured responses to calculate a new set of commands and applies them to the actuators. This cycle is repeated until the vibration level is driven back down to just below the specified threshold. Under ideal conditions, the transfer matrix should not need to be re-identified. Only major changes in the aircraft dynamics would warrant reidentification of the transfer matrix. Changes in the external forces themselves do not necessarily require re-identification.

Determination of the Transfer Matrix. The formulation developed in this section uses two sets of notation. In the first part of this formulation, the matrix components are listed as components of vectors associated with sine and cosine components of a signal or response to emphasize that fact. Once the major components of the formulation are established the formulation converts to a standard indicial notation.

The transfer matrix is based on $M$ responses and $N$ control actuators. Although $M$ is generally equal to or greater than $N$, this is not necessary for the algorithm to work. A harmonic analysis is used to obtain the cosine and sine components of the response as:

$$
\left\{Z_{n}\right\}_{n}=\left\{\frac{2}{K} \sum_{k=1}^{K_{s}} z_{,}(k \Delta \psi) \cos (n k \Delta \psi)\right\}, \quad i=1, M
$$

$$
\left\{Z_{1: s}\right\}_{n}=\left\{\frac{2}{K_{3}} \sum_{k=1}^{K_{1}} z_{1}(k \Delta \psi) \sin (n k \Delta \psi)\right\}, \quad i=1, M
$$

where $z_{1}(k \Delta \psi)$ represents the $i$ th response signal at $k \Delta \psi$ position in the azimuth (time), $n$ is the harmonic of interest (primarily $3 \mathrm{P}$ in the present study), $K$, is the number of samples contained in the digitized response signal, and $\Delta \psi$ is the azimuth angle traveled by the reference blade in the time between samples. The test signals sent to the actuators to identify the transfer matrix are harmonics at the frequency of interest and do not have to be harmonically analyzed. Let these signals be assembled in the column vectors $\left\{\Theta_{\mu k}\right\}_{n}$ and $\left\{\Theta_{j s}\right\}_{n}$ for $j=1, N$.

A $(2 M \times 1)$ vector of the change in response between the baseline response and the response to the test signal is given as

$$
\left\{\begin{array}{l}
\Delta Z_{\mathrm{r}} \\
\Delta Z_{\mathrm{ir}}
\end{array}\right\}=\left\{\begin{array}{l}
Z_{\mathrm{ic}} \\
Z_{\mathrm{is}}
\end{array}\right\}_{\text {iest }}-\left\{\begin{array}{l}
Z_{i c} \\
Z_{\mathrm{is}}
\end{array}\right\}_{\text {base }}, i=1, M
$$

It should be pointed out that in this paper 'baseline response' means the current level of controlled vibrations and not the vibratory response with $\mathrm{HHC}$ off. The corresponding change in the control signal is given by:

$$
\left\{\begin{array}{l}
\Delta \Theta_{j c} \\
\Delta \Theta_{\mu}
\end{array}\right\}=\left\{\begin{array}{l}
\Theta_{j c} \\
\Theta_{\mu s}
\end{array}\right\}_{\text {lest }}-\left\{\begin{array}{l}
\Theta_{\mu} \\
\Theta_{\mu}
\end{array}\right\}_{\text {hase }}, j=1, N
$$

The transfer matrix is then defined as the $2 M \times 2 N$ matrix in the equation

$$
\left\{\begin{array}{l}
\Delta Z_{i r} \\
\Delta Z_{u}
\end{array}\right\}=\left[\begin{array}{ll}
\frac{\Delta Z_{i c}}{\Delta \Theta_{k}} & \frac{\Delta Z_{i c}}{\Delta \Theta_{j s}} \\
\frac{\Delta Z_{s s}}{\Delta \Theta_{k c}} & \frac{\Delta Z_{s s}}{\Delta \Theta_{j s}}
\end{array}\right]\left\{\begin{array}{l}
\Delta \Theta_{j k} \\
\Delta \Theta_{j s}
\end{array}\right\}, i=1, M, j=1, N
$$

which relates changes in control inputs to changes in system responses. Since the system is assumed to be linear, the following relationships are used to reduce the time needed to compute the matrix:

$$
\begin{aligned}
& \frac{\Delta Z_{u}}{\Delta \Theta_{\mu}}=\frac{\Delta Z_{u r}}{\Delta \Theta_{\mu}} \\
& \frac{\Delta Z_{u}}{\Delta \Theta_{\mu}}=-\frac{\Delta Z_{u}}{\Delta \Theta_{\mu}}
\end{aligned}
$$


Vibration Minimization. To minimize vibration it is desired to drive the total responses due to the rotor and the applied HHC toward zero. Similar to equation (3), the change in response associated with an applied HHC may be written as

$$
\left\{\begin{array}{l}
\Delta Z_{i c} \\
\Delta Z_{i s}
\end{array}\right\}=\left\{\begin{array}{l}
Z_{i c} \\
Z_{i r}
\end{array}\right\}-\left\{\begin{array}{l}
Z_{i c} \\
Z_{i s}
\end{array}\right\}_{\text {bese }}, \quad i=1, M
$$

and making use of the transfer matrix allows equation (8) to be written as

$$
\left[\begin{array}{ll}
\frac{\Delta Z_{i c}}{\Delta \Theta_{j c}} & \frac{\Delta Z_{i c}}{\Delta \Theta_{j i}} \\
\frac{\Delta Z_{i r}}{\Delta \Theta_{j r}} & \frac{\Delta Z_{i s}}{\Delta \Theta_{j r}}
\end{array}\right]\left\{\begin{array}{l}
\Theta_{j c} \\
\Theta_{j}
\end{array}\right\}_{c i n}=\left\{\begin{array}{l}
Z_{i c} \\
Z_{i s}
\end{array}\right\}_{c o n}-\left\{\begin{array}{l}
Z_{i c} \\
Z_{i s}
\end{array}\right\}_{\text {hase }}
$$

Now since it is desired to minimize the response after the control is applied, the quantity that must be minimized is

$$
\begin{aligned}
z_{k}= & T_{k i} \theta_{i}+\left(z_{n}\right)_{k} \\
& =\left[\begin{array}{ll}
\frac{\Delta Z_{i c}}{\Delta \Theta_{j c}} & \frac{\Delta Z_{i c}}{\Delta \Theta_{j s}} \\
\frac{\Delta Z_{i s}}{\Delta \Theta_{j c}} & \frac{\Delta Z_{i r}}{\Delta \Theta_{j k}}
\end{array}\right]\left\{\begin{array}{l}
\Theta_{j k} \\
\Theta_{k s}
\end{array}\right\}_{c o n}+\left\{\begin{array}{l}
Z_{i c} \\
Z_{i s}
\end{array}\right\}_{\text {base }} \\
& i=1, M ; j=1, N ; k=1,2 M ; l=1,2 N
\end{aligned}
$$

where $z$ is a $(2 M \times 1)$ vector that represents the response associated with the current control signal $(M$ cosine components and $M$ sine components). Notice at this point in the formulation that it was advantageous to convert to standard indicial notation with new indices $k$ and $l$ running twice the number of $\mathrm{i}$ and $\mathrm{j}$. From this point forward, $k$ is understood to cycle through $M$ cosine and $M$ sine components of the response points ( $2 M$ total) and $l$ is understood to cycle though the $N$ cosine and $N$ sine components of the control points ( $2 N$ total).

It should be noted that the development given above has implicitly assumed only one harmonic of interest for vibration reduction. If there are two harmonics targeted for reduction, there will be two cosine terms and two sine terms for each physical actuator and/or response point and the size of all matrices and vectors doubles.

Performance Characterization. A scalar performance index is now introduced as

$$
J=z_{k}^{T} R_{k k} z_{k}+\theta_{1}^{T} Q_{k} \theta_{l}
$$

where $z$ is the response associated with the current control signal, $\theta$ is the current control signal, and $R$ and $Q$ are diagonal weighting matrices used to scale the performance index:

$$
\begin{gathered}
R_{k k}=\frac{1}{\left(z_{m}\right)_{k}^{2}} \\
Q_{n}=\frac{1}{\left(\theta_{m}\right)_{l}^{2}}
\end{gathered}
$$

where the $\left(z_{m}\right)_{k}$ are user-defined inputs which should reflect the target response level for the $i$ th response point and the $\left(\theta_{m}\right)_{i}$ are user-defined inputs which should reflect a maximum allowable control input for the $/$ th actuator.

Combining equations (10) and (1) gives the performance index desired for minimization as

$$
J=\left(T_{k l} \theta_{i}+\left(z_{b}\right)_{k}\right)^{T} R_{k k}\left(T_{k l} \theta_{i}+\left(z_{b}\right)_{k}\right)+\theta_{i}^{T} Q_{l l} \theta_{t}
$$

where $T$ is the transfer matrix, $\theta$ is the control signal, and $z_{b}$ is the baseline response. The value of the control signal which will minimize $J$ can be determined through expansion of the above expression and taking the derivative of $J$ with respect to the control input $\theta$ :

$$
\left(\frac{\partial J}{\partial \theta}\right)_{l}=\left(z_{k}\right)_{k}^{T} R_{k k} T_{k l}+T_{l k}^{I} R_{k k} T_{k l} \theta_{i}+Q_{l l} \theta_{l}=(0)
$$

from which the control input which will satisfy this expression is given as

$$
\theta_{i}=-\left[T_{l k}^{T} R_{k k} T_{k l}+Q_{l l}\right]^{-1}\left[T_{l k}^{T} R_{k k}\left(z_{b}\right)_{k}\right]
$$

which may be written in control law form as:

$$
\theta_{1}=-K_{l k}\left(z_{b}\right)_{k}
$$

where $K$ is the control matrix. For a linear system, application of equation (17) gives a se: of control signals which minimizes $J$. As mentioned earlier when discussing Figure 6, to account for any system nonlinearities, only a fraction of the calculated change in control signal is added to the existing control signal and applied to the actuators. This piecewise linear stepping is repeated until the threshold is reached.

\section{TEST CONDITIONS AND SYSTEM CONFIGURATIONS}

The experimental investigation was conducted in the NASA Langley Transonic Dynamics Tunnel which is a continuous flow, single return, variable pressure tunnel having a test section 16 feet square with cropped corners. The control room and test section walls are provided with large windows for close viewing of the model. The tunnel is capable of operation at stagnation pressures from near vacuum to slightly above atmospheric and Mach numbers up to 1.2. Either air or a heavy gas can be used as the test medium. The present study was conducted in air under near atmospheric conditions at free-stream Mach numbers less than 0.30 . 
Table 2. Description Of Runs

\begin{tabular}{|c|c|c|c|}
\hline Run & Description & $\begin{array}{l}\text { Tunnel } \\
\text { Speed } \\
\text { (knots) }\end{array}$ & $\begin{array}{c}\text { Rotor } \\
\text { Speed } \\
\text { (knots) }\end{array}$ \\
\hline 1 & $\begin{array}{l}\text { Frequency sweeps of } \\
\text { actuators }\end{array}$ & 0 & rotor off \\
\hline 2 & $\begin{array}{l}\text { Frequency sweeps of } \\
\text { actuators }\end{array}$ & $0-100$ & 742 \\
\hline 3 & Track and balance & 100 & 742 \\
\hline 4 & Open loop tests & 100 & 742 \\
\hline 5 & $\begin{array}{l}\text { Open and closed loop } \\
\text { tests }\end{array}$ & 100 & 742 \\
\hline 6 & Closed loop tests & 150 & 742 \\
\hline 7 & Frequency sweep & 100 & 742 \\
\hline 8 & $\begin{array}{l}\text { 1P flapping } \\
\text { investigation }\end{array}$ & 100 & 742 \\
\hline 9 & $\begin{array}{l}\text { Closed-loop velocity } \\
\text { sweeps }\end{array}$ & $0-150$ & 742 \\
\hline 10 & $\begin{array}{l}\text { Closed-loop velocity } \\
\text { sweeps }\end{array}$ & $0-150$ & 742 \\
\hline 11 & $\begin{array}{l}\text { Closed-loop velocity } \\
\text { sweeps }\end{array}$ & $0-150$ & $742-888$ \\
\hline 12 & $\begin{array}{l}\text { Gain-schedule data } \\
\text { collection }\end{array}$ & $0-150$ & $742-888$ \\
\hline 13 & $\begin{array}{l}\text { Gain-schedule data } \\
\text { collection }\end{array}$ & $0-150$ & $742-888$ \\
\hline 14 & Combined $1 \mathrm{P} / 3 \mathrm{P}$ & 100 & $660-800$ \\
\hline 15 & MAVSS time histories & $0-150$ & $660-742$ \\
\hline
\end{tabular}

The model was configured in the airplane mode for axial flight and was unpowered for these tests. For windmilling rotors, the desired rotor rotational speed is set by varying collective pitch, which must increase with wind-tunnel velocity to maintain a given constant RPM. Cyclic pitch was used to maintain zero rotor flapping with respect to the mast. As a matter of procedure, once the aircraft was trimmed no additional pilot commands were applied while the HHC system was activated.

Testing was performed in the sequence listed in Table 2 , which lists all the runs that were made with the model. Runs 1 to 8 were used for rotor track and balance adjustments, determination of the dynamic properties of the model with the new hydraulic-based actuation components, and checkout of the active control system in open-loop configurations (no response feedback). Runs 9 to 15 were data runs.

Closed-loop tests required evaluation of a performance index to be used by the active control system as a measure of success in reducing vibration. There are two components in the performance index as defined in equation (14), one dealing with the responses and one dealing with the control inputs. For these tests, the number of inputs $(N)$ was either 1,3 , or 4 . When $N=1$

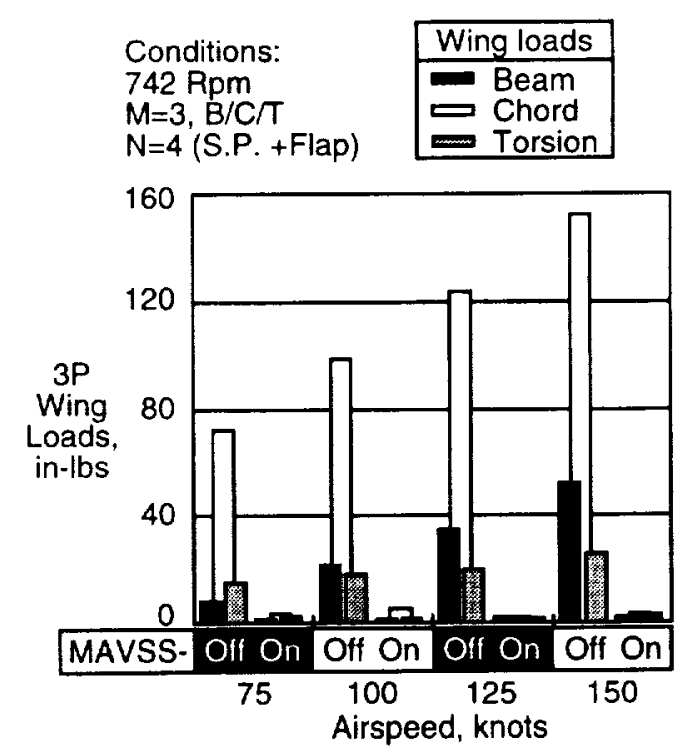

Figure 7. 3P wing loads as a function of airspeed.

only the flaperon actuator was used, when $N=3$ only the 3 swashplate actuators were used, and when $N=4$ the flaperon and 3 swashplate actuators were used simultaneously.

The most common setup for responses was $M=3$, where the beam, chord, and torsion components of the wing root vibratory loads were used. However, several other types of response point configurations were also considered, so the nomenclature of ' $M=i \quad A / B / \ldots$ ' is adopted throughout this report; where $i$ is the number of response points considered and $A / B / \ldots$ are indicators of what each of the $i$ response points are for the setup. For example, the most common setup of using the 3 wing root loads as the response points is labeled as $M=3 B / C / T$ where $B$ is wing beam bending, $C$ is wing chord bending, and $T$ is wing torsion. The remaining 3 points considered in some setups were accelerometers at the pylon center of gravity in the lateral direction $(C G L)$, at the pylon conversion axis in the normal direction $(C A N)$ or at the pylon conversion axis in the axial direction $(C A A)$. The response measurement locations are shown in the diagram of Figure [4].

\section{RESULTS AND DISCUSSION}

\section{Suppression of 3P Vibratory Loads}

HHC Performance. Higher harmonic control was very effective in suppressing the fixed-system vibratory responses of the tiltrotor model in airplane mode. The MAVSS control system, when configured to reduce $3 \mathrm{P}$ harmonics of the wing loads, was generally able to reduce the wing beam, chord, and torsion load components simultaneously by 85 to 95 percent over the entire range of rotor speeds and tunnel airspeeds considered. Representative results are shown in Figure 


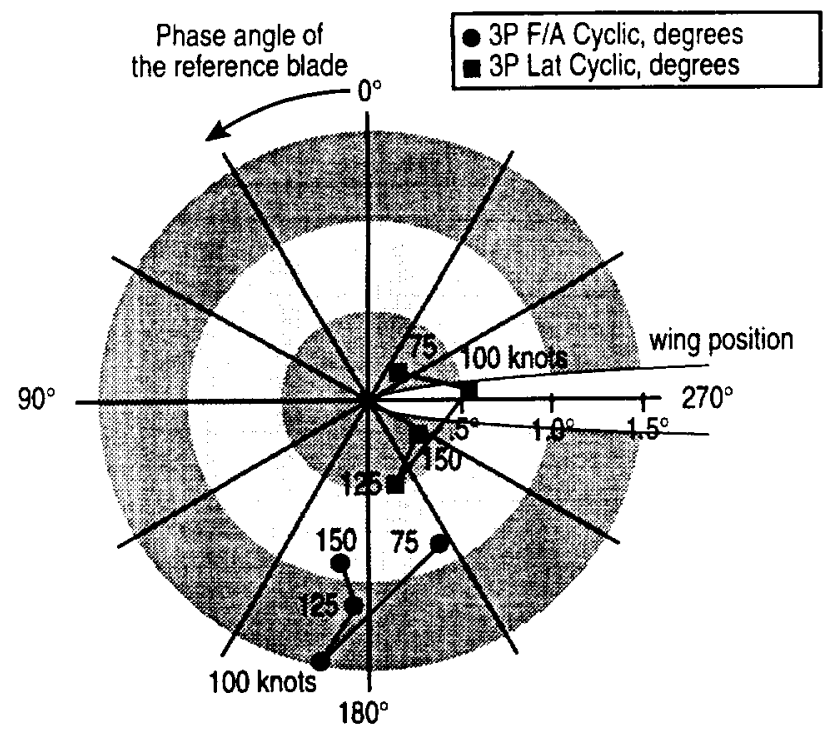

Figure 8. Typical 3P cyclic control angles as a function of airspeed.

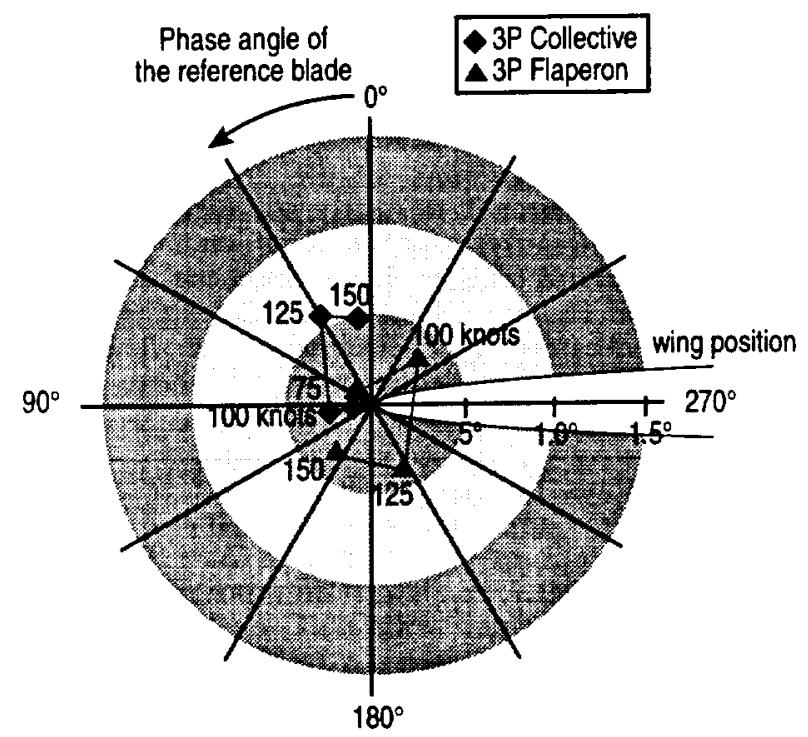

Figure 9. Typical 3P collective control and flaperon angles as a function of airspeed.

[7] for the case $M=3$ (wing beam, chord and torsion load feedback equally weighted) and $N=4$ (activation of both the swashplate and flaperon). The plot shows that with HHC turned off, the $3 \mathrm{P}$ vibratory loads increase with airspeed, and that the chordwise vibratory load is substantially higher than are the beam and torsion load components. The vibratory loads in the wing chord direction are larger than the wing beam and torsion load components because the chord component of load is affected mainly by the changes in rotor thrust (actually drag for a windmilling rotor) while the beam and torsion components are influenced primarily by the rotor inplane forces, and the vibratory components of rotor thrust tend to be much larger than the vibratory components of the rotor inplane forces. When the control system is activated, the $3 \mathrm{P}$ load in all three wing load components is shown to decrease significantly over the same range of airspeeds. The indicated load reductions vary from 85 to 95 percent of the corresponding uncontrolled values. These results are similar, in terms of magnitude of vibratory load reduction, to those obtained for a model $\mathrm{CH}-47$ 3bladed articulated rotor system in reference 13.

HHC Amplitude and Phasing. Limits on the maximum amplitudes of HHC excitation for this test were placed at \pm 3 degrees for the flaperon and \pm 2 degrees for the swashplate. Amplitudes required for $\mathrm{HHC}$ in this test were generally well below these limits, as indicated in Figures [8] and [9] which correspond to the results shown in Figure [7]. As shown, the amplitudes (measured half-peak-to-peak) of the fore/aft cyclic control are predominant as compared to the amplitudes of the lateral cyclic, collective, and flaperon. These latter three control amplitudes generally remain at or below one-half degree, while the $3 \mathrm{P}$ fore/aft cyclic varies from .8 to 1.5 degrees. These results are consistent with the physical source of the vibration as is explained in the following paragraph.

To understand how the swashplate motions shown in Figures [8] and [9] reduce vibration, consider the effect of the wing on the rotor inflow angle as shown in Figure [10]. The inflow results are from reference 37 in which a panel method (VSAERO) was used to model a full-scale V-22 at 313 knots airspeed (corresponding to the $1 / 5$-scale model at about 140 knots) and zero angle of attack. This plot shows the predicted azimuthal variation of inflow angle for blade stations at $60 \%$, $80 \%$, and $100 \%$ radius, and clearly indicates a large effect of the wing on the flowfield in the azimuthal range of 210-330 degrees, with first a large increase in inflow angle as a blade approaches the wing, and $t: n$ a large decrease in inflow angle after passing the wing. The spike in the inflow angle curve at the $100 \%$ radius near the 220 degree azimuth is due to fuselage interference effects. To reduce vibration, the azimuthal variation in lift (associated with the indicated changes in inflow angle) must be reduced by maintaining a near constant azimuthal angle of attack on the blade sections. The increase in inflow angle before $\psi=270^{\circ}$ and the decrease in the inflow angle after $\psi=270^{\circ}$ must then be accompanied by corresponding increases and decreases in the blade pitch. The plot of Figure [11] shows the contribution of the collective and cyclic pitch components to the total blade root pitch corresponding to the $150 \mathrm{knot}$ airspeed in Figures [8] and [9]. This airspeed is near the full-scale airspeed on which Figure [10] is based. The shape of the total pitch angle curve is seen to be similar to the shape of the inflow angle curve in the azimuthal range near the wing where the peak inflow occurs. 


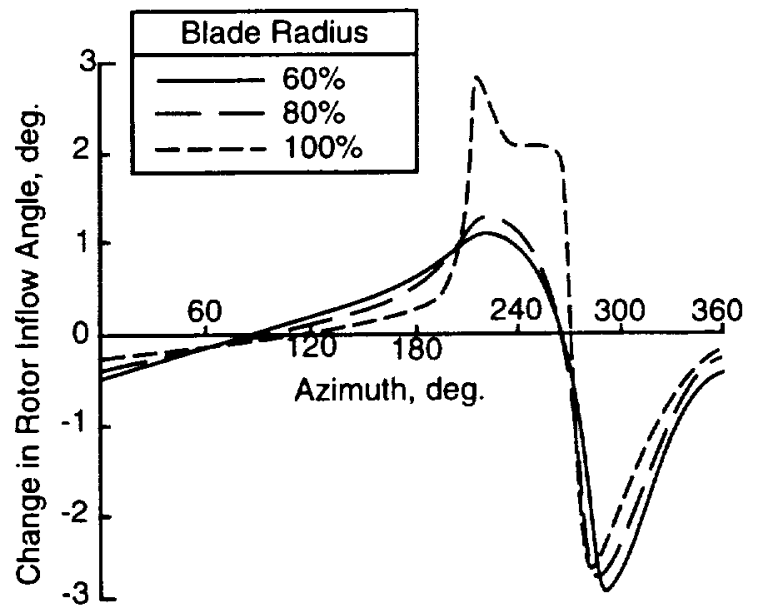

Figure 10. Typical rotor inflow angle variation with azimuth.

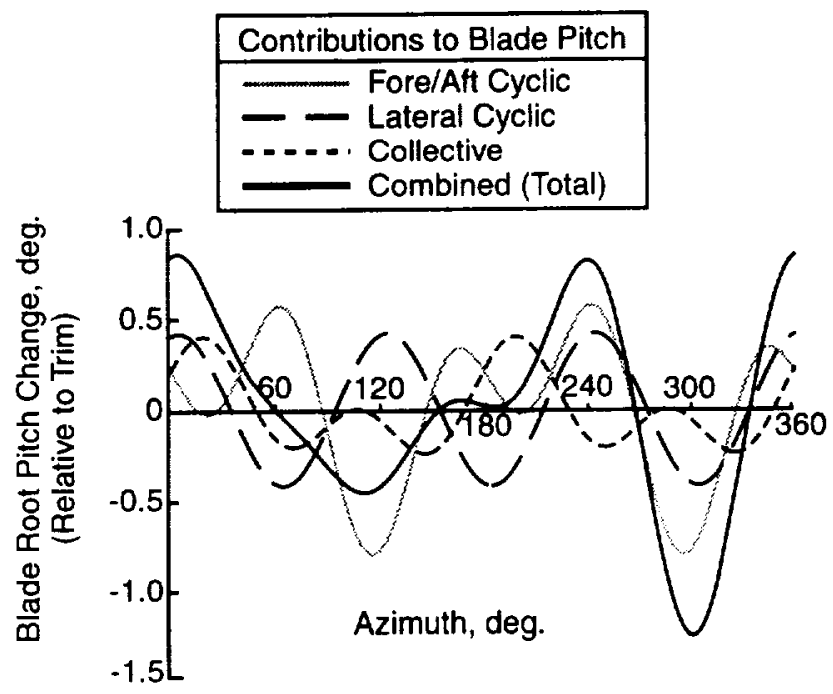

Figure 11. HHC components of blade root pitch.

Effect of Actuator and Response Selection. One aspect of the HHC system which needed to be investigated was the effect on the response associated with the number and choice of control points (actuators) used for input and the number and choice of response points (strain and acceleration measurements) used for feedback. Based on the principle of superposition for linear systems, one would expect that the number of control points should equal the number of response points. However, there are two reasons why this need not be the case for the present system: (1) the present system may be nonlinear, and (2) the response points considered may not be independent. As a simple example of the latter case, consider the vibration of a cantilevered wing with two response points for feedback and a single actuator control point. If two

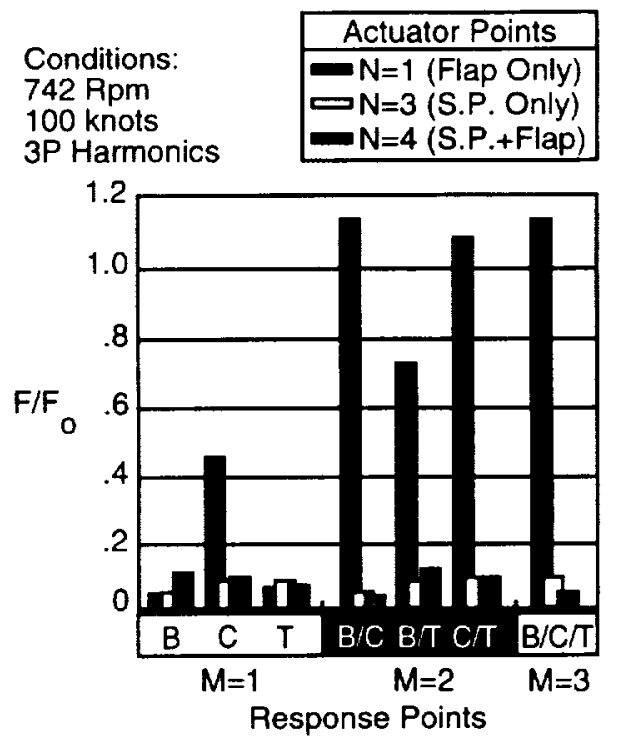

Figure 12. Load factors for several cases of HHC.

strain gages are both oriented to measure bending in the same direction, then a single actuator oriented in the same beam bending direction would likely have a high degree of success at reducing vibration at both locations. If the orientation of the response points considered are orthogonal, or nearly so, such that one gage measures primarily beam bending loads and the other primarily chord bending loads, then the actuator is likely to be much less effective in reducing at least one of those vibratory responses, no matter how the actuator is oriented with respect to those two directions.

Figure [12] shows the level of vibration reduction achieved in terms of a scalar load factor $F / F_{0}$ for several combinations of control points $(N=1,3,4)$ and response points $(M=1,2,3)$. This term represents a ratio of the total vibratory load with $\mathrm{HHC}$ on to that with HHC off, and $F$ itself represents a resultant magnitude of the load components as given by

$$
F=\sqrt{\sum_{i=1}^{M} f_{i}^{2}}
$$

where each $f$ is the load considered in the performance index corresponding to a particular case.

The plot of Figure [12] shows that the flaperon by itself $(N=1)$ can be very effective at reducing vibration levels in a single load component, especially the beam and torsion loads. For the flaperon-only case, the chord load component was not reduced as much as the beam and torsion components because more amplitude of flaperon motion is required than was allowed in this test $( \pm 3$ degrees limit). Results from an earlier test (Ref. 34) indicated that the flaperon-only case could lower the chordwise 3P load to about the same level as that associated with the beam and torsion components 


\begin{tabular}{l|l|c|}
\multicolumn{1}{c|}{} & \multicolumn{2}{c|}{ Response Points } \\
\cline { 2 - 3 } & $\begin{array}{c}\text { Loads from } \\
\text { strain gages }\end{array}$ & $\begin{array}{c}\text { Pylon } \\
\text { accelerometers }\end{array}$ \\
\hline $\begin{array}{l}\text { Conditions: } \\
M=6 \\
N=4 \text { (S.P+Flap) }\end{array}$ & $\begin{array}{l}\text { Wing Beam } \\
\text { Wing Chord }\end{array}$ & CGL \\
Wing Torsion & - CAN \\
\hline
\end{tabular}

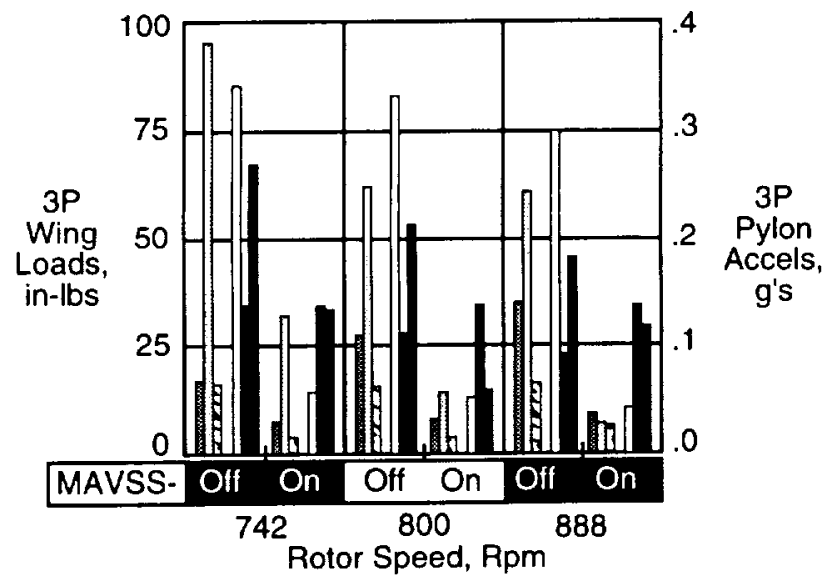

Figure 13. 3P loads and 3P accelerations for HHC with six response points of feedback.

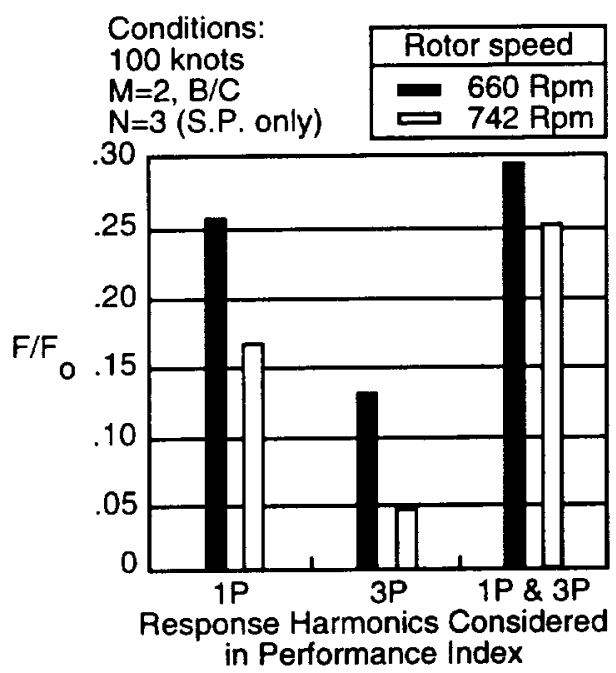

Figure 14. Load factor associated with choice of harmonics in the performance index.

if given enough flap amplitude ( \pm 6 degrees). However, a flaperon-only controller was not effective at reducing vibration in multiple load components simultaneously.

The effectiveness of the controller in reducing multiple loads simultaneously greatly improves for the swashplate alone $(N=3)$ and the swashplate plus flaperon together $(N=4)$, as is shown in Figure [12]. The active control system is seen to have about the same level of effectiveness for the $N=3$ and $N=4$ setups no matter how many response point are considered for feedback, up to $M=3$. In general, it is observed that an order of magnitude reduction in the $3 \mathrm{P}$ loads is ot-ained when $N \geq M$. The plot of Figure [12] also st ivs that the reduction associated with use of the flaperon and swashplate together can be either more or less effective that the swashplate alone, which serves to illustrate the manner in which the control algorithm operates. It is much like a classical optimization problem in which a global minimum is sought, but the solution procedure may converge to a local minimum. Consider, for example, the $M=1$ beam response case shown and observe that the flaperon-only case has a lower 3P beam bending load than the swashplate plus flaperon case. Certainly, one possible solution to the control system is to turn off the higher harmonic swashplate commands and send control signals only to the flaperon, in which case the result of the flaperononly controller would be duplicated. Just as the final solution to a classical optimization problem depends on the starting position in the design space (and other stepping parameters), the final solution to the vibration reduction problem using the MAVSS control algorithm depends on the initial transfer matrix (and other stepping parameters).

Data was also obtained for a case where $M=6$ ( 3 wing loads and 3 pylon accelerations) and $N=4$ (swashplate and flaperon control). As shown in Figure [13], the control system is less effective than for the $M=3$ case in terms of its capability to reduce all the load components simultaneously. However, the largest contributors to the $3 \mathrm{P}$ load and acceleration, namely wing chord bending, pylon lateral acceleration at the center of gravity $(C G L)$, and pylon axial acceleration at the conversion axis $(C A A)$, were all reduced

significantly, generally by 50 percent or more. The normal acceleration at the conversion axis $(C A N)$ is shown to increase slightly in each case, probably because the largest vibration levels were associated with the chordwise bending direction, and thus those measurements were much more influential in reducing the performance index than the normal acceleration.

Comparison of 1P, 3P, and Combined 1P/3P Vibration Suppression

The MAVSS algorithm may be configured to perform vibration reduction on any harmonic or combination of harmonics of the response feedback which the associated hardware can support. Since the windtunnel model had some inherent IP imbalance that increased with airspeed, it was of interest to evaluate the HHC capabilities for reduction of the $1 \mathrm{P}$ and a combination of the $1 \mathrm{P}$ and $3 \mathrm{P}$ harmonics of wing loads. This section of the paper examines the effects of HHC on the total oscillatory (half-peak-to-peak) loads and the associated harmonics of the vibratory loads for three HHC system configurations. All three configurations use wing beam and chord load feedback $(M=2)$ and swashplate-only control $(N=3)$ but differ in terms of the harmonics of the loads which are considered. This setup was used for the comparison 


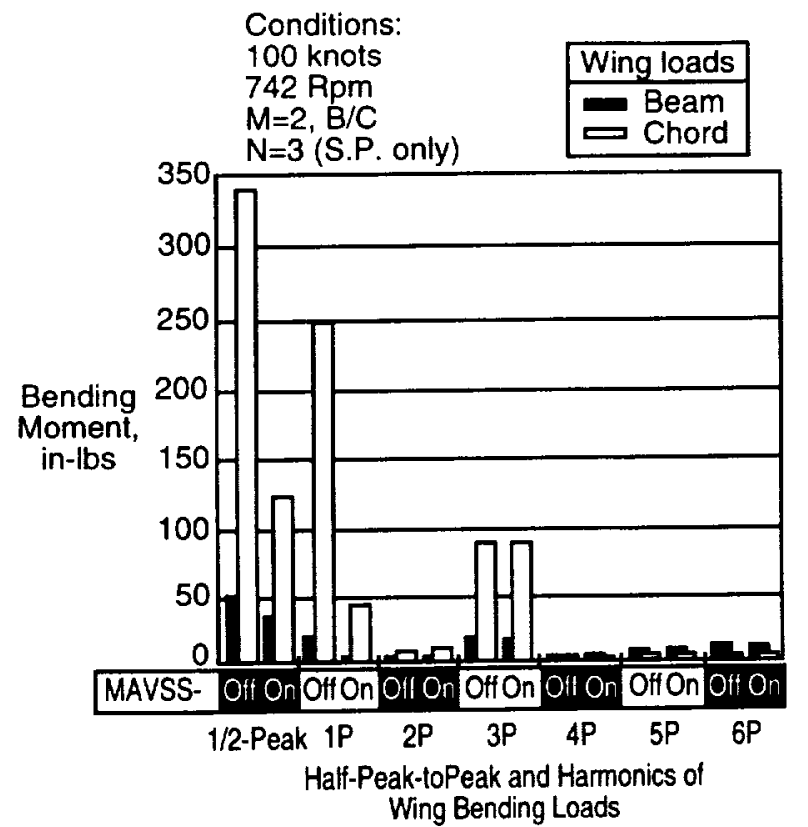

Figure 15. Effect of HHC on harmonic spectrum with IP performance index.

because $M=2$ was the maximum number of feedback responses for which the combination of $1 \mathrm{P}$ and $3 \mathrm{P}$ vibration reduction could be performed using the present hardware setup.

HHC Performance. The bar chart of Figure [14] shows the load factor associated with the use of wing beam and chord load feedback and minimization of $1 \mathrm{P}$ loads, $3 \mathrm{P}$ loads, and combined 1P/3P loads, respectively. Two rotor speeds are considered, the model-scale design rotor speed for airplane mode cruise of 742 RPM and a rotor speed chosen to amplify the 1P loads, $660 \mathrm{RPM}(11 \mathrm{~Hz})$ which is near the natural frequency of the wing fundamental chord mode. For the conditions considered, Figure [14] shows that 1P loads were reduced considerably $(75-85 \%)$, although not as much as the 3P loads (85-95\%). The combined IP and 3P loads were reduced almost as much as the $1 \mathrm{P}$ loads alone $(70-75 \%)$. These results demonstrate the ability of the HHC system to reduce multiple load components simultaneously using multiple $\mathrm{HHC}$ inputs.

For the 742 RPM cases discussed in the preceding paragraph, the effect of the active system on the harmonic spectrum up to $6 \mathrm{P}$ is shown in Figures [15] [17]. Figure [15] shows that significant reductions in the $1 \mathrm{P}$ components of vibration were gained with very little impact on the other harmonics of the wing beam and chord loads. Furthermore, since the $1 \mathrm{P}$ loads were dominant in this frequency range, the half-peakto-peak loads were significantly reduced as well. It should be noted (Figure [16]) that reductions in the 3P loads came at the expense of increased IP loads. The half-peak-to-peak loads for the chord direction actually increased in this case because of the increase in the $1 \mathrm{P}$ chord loads. Combining the $1 \mathrm{P}$ and $3 \mathrm{P}$ loads in the performance index produced results very different from

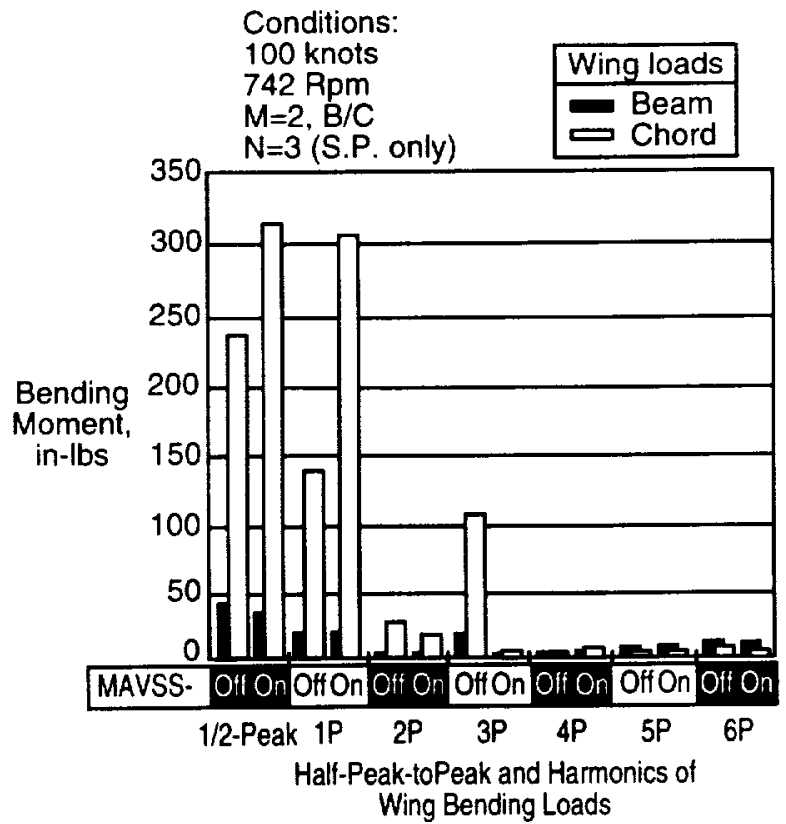

Figure 16. Effect of HHC on harmonic spectrum with 3P performance index.

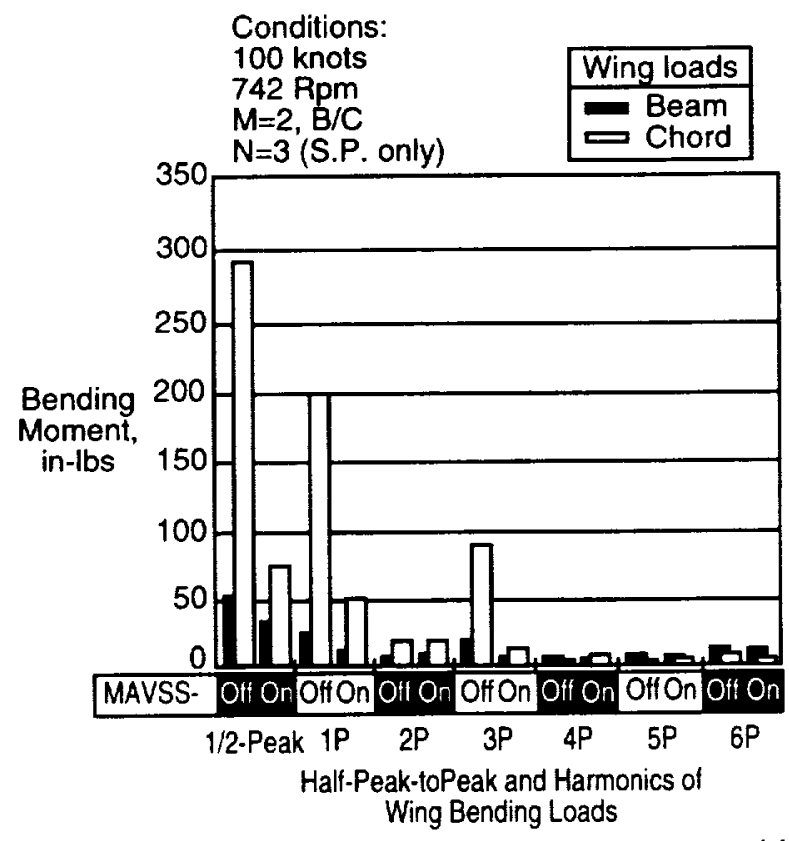

Figure 17. Effect of HHC on harmonic spectrum with combined $1 \mathrm{P} / 3 \mathrm{P}$ performance index.

either of the other two cases. Figure [17] shows that both the IP and 3P harmonics of the loads can be significantly reduced simultaneously. The resulting half-peak-to-peak loads were reduced substantially as well. 


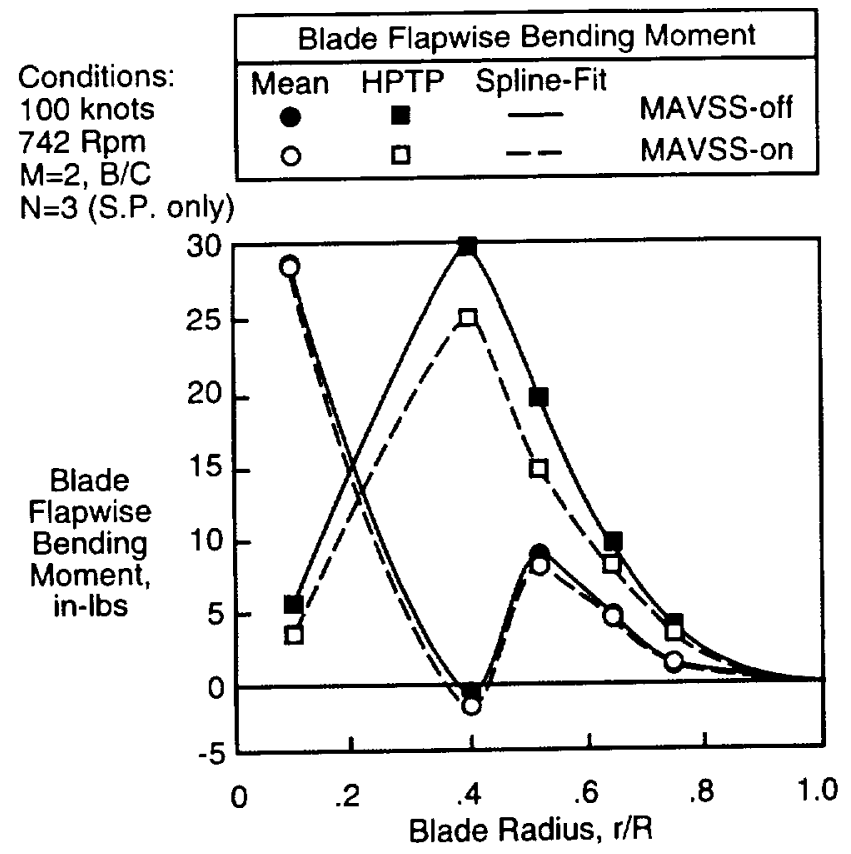

Figure 18. Steady and half-peak-to-peak flapwise blade loads associated with $3 \mathrm{P}$ performance index.

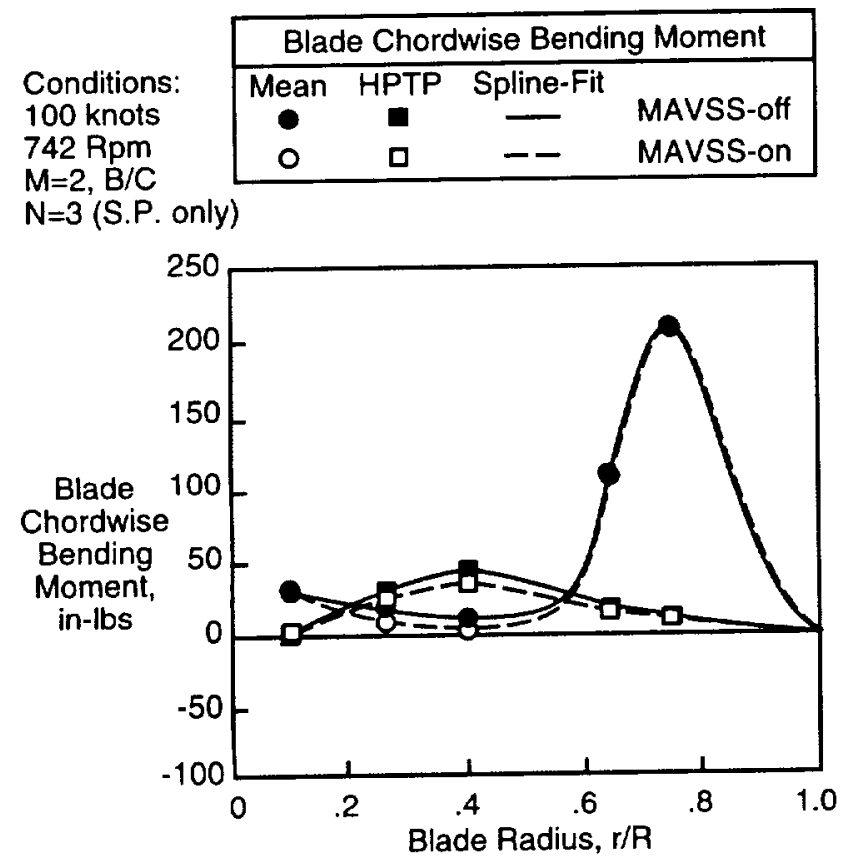

Figure 19. Steady and half-peak-to-peak chordwise blade loads associated with $3 \mathrm{P}$ performance index.

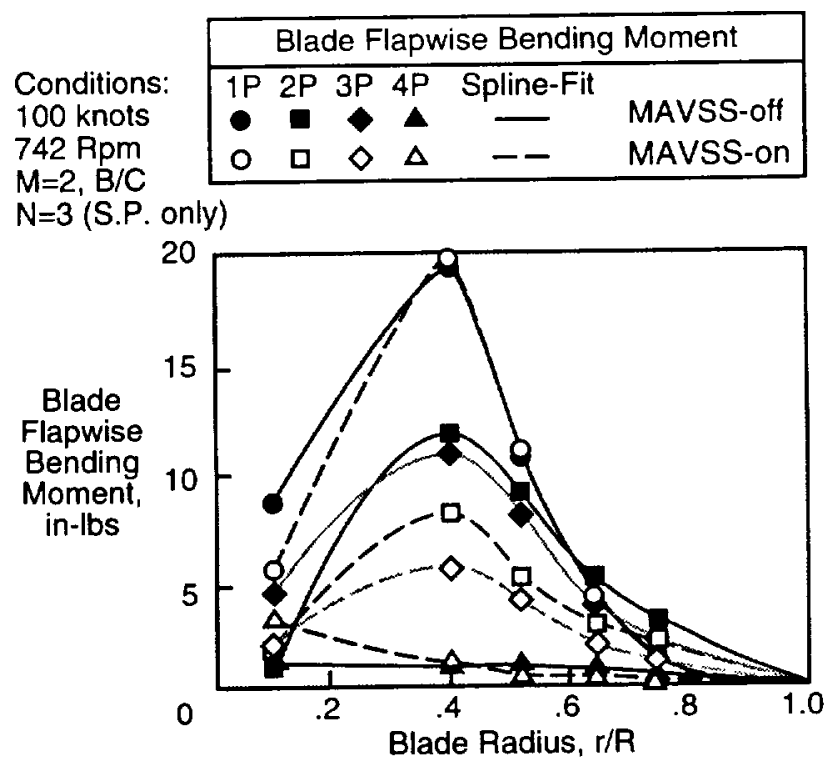

Figure 20. Harmonics of flapwise blade loads associated with $3 \mathrm{P}$ performance index.

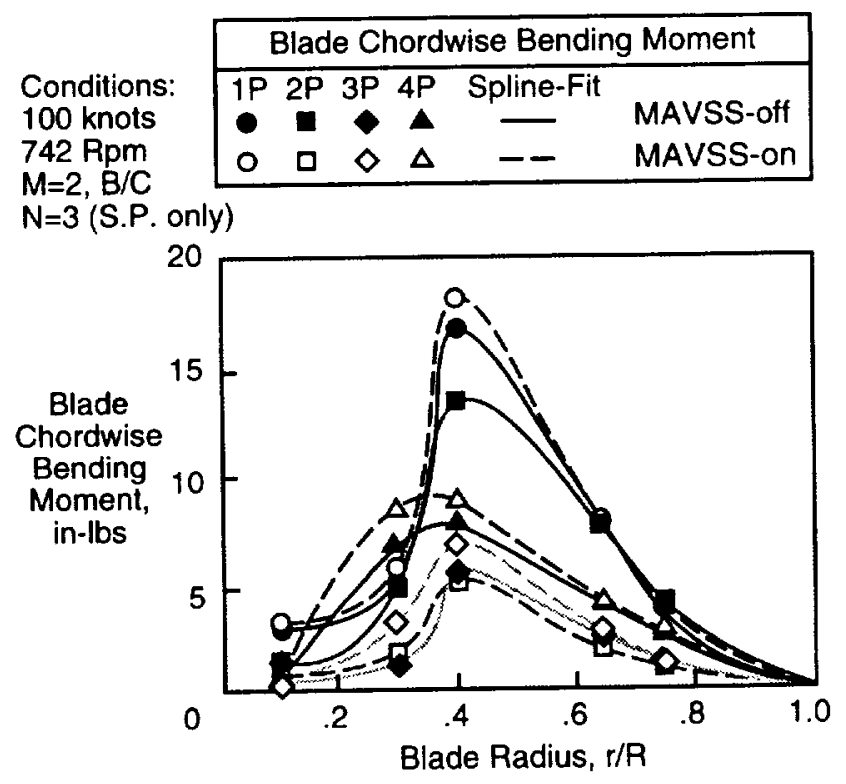

Figure 21. Harmonics of chordwise blade loads associated with $3 \mathrm{P}$ performance index. 
Control System Reaction to Dynamic Changes in Operating Conditions

The MAVSS algorithm is designed to be adaptive to changes in the dynamics of the system. As mentioned earlier when discussing Figure [6], MAVSS does this by continually evaluating the performance index $J$ and comparing it to the user-specified threshold value. If $J$ increases above the threshold value, and there is no improvement after a preset number of reapplications of the control law, the transfer matrix is reidentified. The dynamics of a system can be affected by changes in either the structure or the flight conditions. In the present investigation, rapid changes in the model operating conditions (rotor speed and tunnel velocity) were used to evaluate the HHC algorithm for its effectiveness in adapting to changes in the system dynamics. Results of this part of the study showed that the algorithm is very robust with respect to adapting to rapid changes in either airspeed, rotor speed, or a combination of both, and reidentification of the system transfer matrix was rarely required. Under separate changes in airspeed (50 knots over a 10 second interval) and rotor speed (130 RPM over a 5 second interval), the algorithm did not need to reidentify the transfer matrix, but was still very effective at reducing vibrations using the initial transfer matrix which was identified at some nominal flight condition. In an attempt to exercise the portion of the algorithm which calls for a reidentification of the system transfer matrix, the airspeed and rotor speed were swept simultaneously at rates comparable to those noted above, and in a few cases the algorithm did reidentify the transfer matrix. There was no significant degradation in the existing vibration levels during this process.

\section{Gain-Scheduled Control}

A gain-scheduled controller was also evaluated for its effectiveness in reducing vibrations under both steadystate and varying flight conditions. The 3-D table of gains needed for this study was formed from the HHC inputs (gains) computed my MAVSS at three rotor speeds (randomly selected for each airspeed) for each of four airspeeds $(75,100,125$, and $150 \mathrm{knots})$. The HHC algorithm was then configured to interpolate from this table the required control signals for any combination of rotor speed and airspeed for which the wind-tunnel model could be operated. The performance of the controller was found to be extremely similar to that of the adaptive HHC system in terms of its vibratory loads reduction capability and its reaction time during rapid changes in model operating conditions. This is because the adaptive algorithm rarely required reidentification of the system transfer matrix, and because there is very little difference between the time required to interpolate an HHC signal from a table (gain-schedule version) and the time required to calculate an HHC signal from the response feedback (adaptive version). Only during a reidentification of the system transfer matrix would the adaptive algorithm take a significantly longer time to react than the gain-scheduled algorithm, but since reidentification is a rare occurrence there was little difference in performance.

\section{Effect of HHC on Blade and Pitch Link Loads}

General Trends. A general effect associated with the use of $\mathrm{HHC}$ in these tests was a reduction in the peak oscillatory blade bending loads, and an increase in oscillatory pitch link loads. The increases or decreases observed are directly attributable to changes in the harmonics of the blade loads affected by the active control.

Examples of HHC Effects on Blade Loads. The effects of HHC activation on the blade spanwise loads (flapwise and chordwise bending moments) and pitch link loads are examined in this section for two cases: both have the $M=2 B / C, N=3$ control-system setup, but the first case considers only $3 \mathrm{P}$ wing beam and chord loads in the performance index (vibration reduction results shown in Figure [16]) and the second case includes both the $1 \mathrm{P}$ and $3 \mathrm{P}$ wing beam and chord loads in the performance index (vibration reduction results shown in Figure [17]).

The blade loads associated with the 3P-only case are shown in Figures [18]-[21]. The plots of Figures [18] and [19] show the mean and half-peak-to-peak (oscillatory) blade flapwise and chordwise moments, respectively, with HHC off and on. These results show very small reductions in the mean loads, but the peak oscillatory bending moment is shown to drop significantly. The HHC-associated reductions in the peak oscillatory loads which occur at $r / R=0.4$ are by $20 \%$ for the flapwise moment and by $25 \%$ for the chordwise moment. The harmonic contributions to these oscillatory moments are shown in Figures [20] and [21]. For flapwise moments there is a significant decrease in the $2 \mathrm{P}$ and $3 \mathrm{P}$ harmonics of the blade load and for the chordwise moments there is a significant decrease in the $2 \mathrm{P}$ and $4 \mathrm{P}$ components of the blade loads.

Similar results were obtained for this configuration using both $1 \mathrm{P}$ and $3 \mathrm{P}$ wing loads in the performance index for vibration reduction, as shown in Figures [22][25]. Figures [22] and [23] show the mean and halfpeak-to-peak (oscillatory) blade flapwise and chordwise moments, respectively, with MAVSS off and on. Similar to the results shown for the 3P-only case, there is little difference in mean loads, but the peak oscillatory bending moment drops significantly.

Interesting differences between the 3P-only case and the combined $1 \mathrm{P} / 3 \mathrm{P}$ case are evident in the harmonics of the blade loads. The harmonics of the flapwise bending loads associated with the $1 \mathrm{P} / 3 \mathrm{P}$ case are shown in Figure [24]. Note that the 2P blade flapwise bending moment is reduced substantially more than the 2P blade flapwise bending moment associated with the 3P-only case (Figure [20]). Also, the 3P blade 


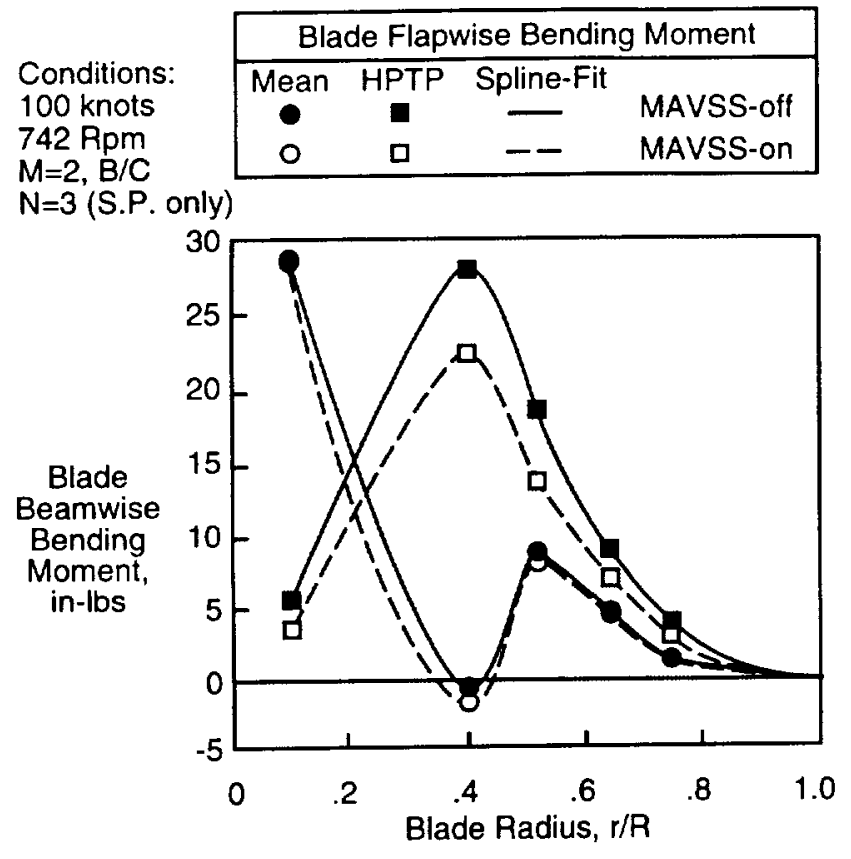

Figure 22. Steady and half-peak-to-peak flapwise blade loads associated with combined $1 \mathrm{P} / 3 \mathrm{P}$ performance index.

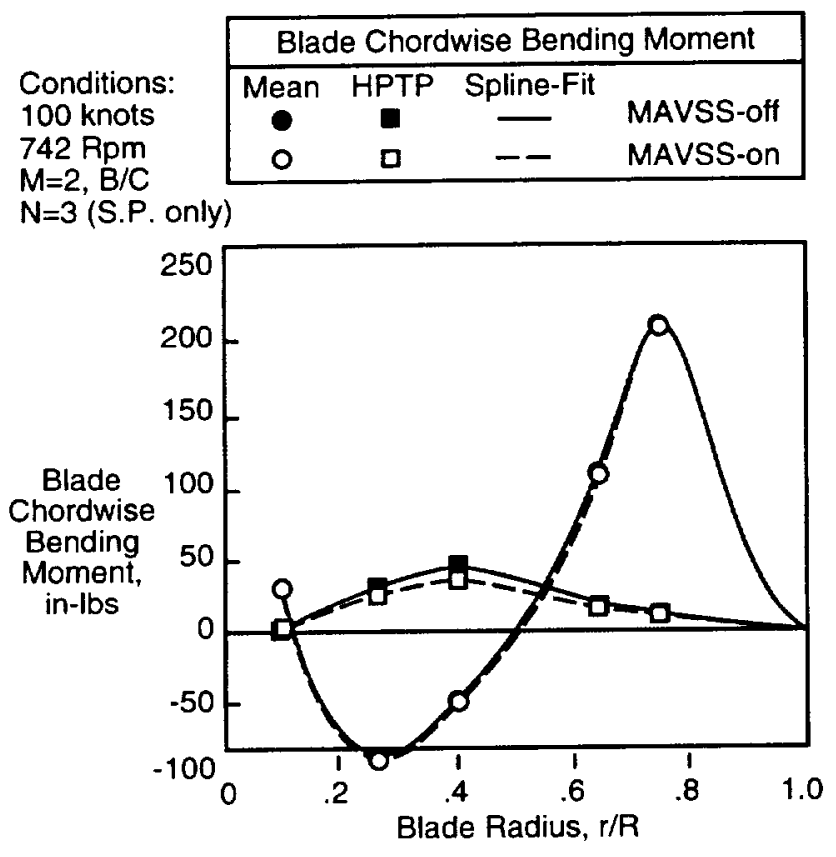

Figure 23. Steady and half-peak-to-peak chordwise blade loads associated with combined 1P/3P performance index.

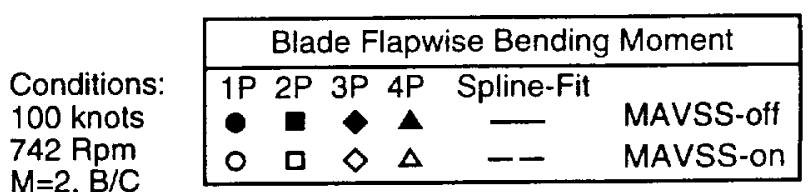

$M=2, B / C$

$\mathrm{N}=3$ (S.P. only)

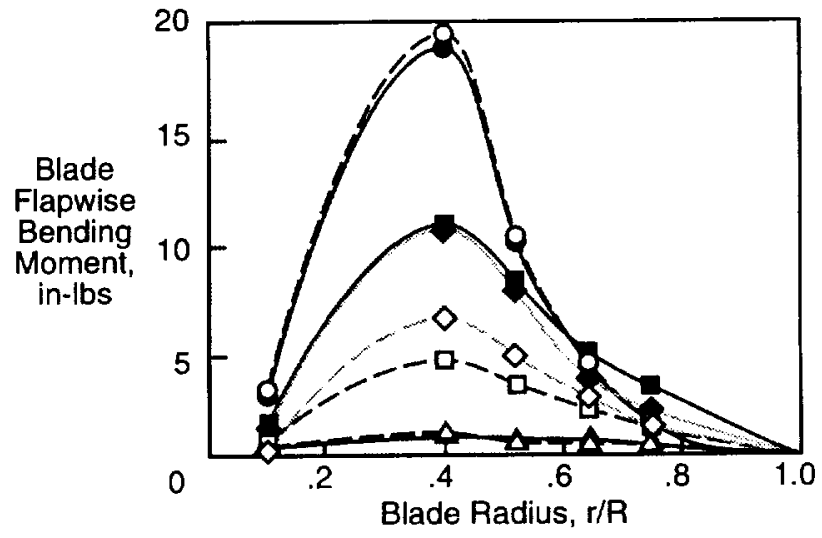

Figure 24. Harmonics of flapwise blade loads associated with combined $1 \mathrm{P} / 3 \mathrm{P}$ performance index.
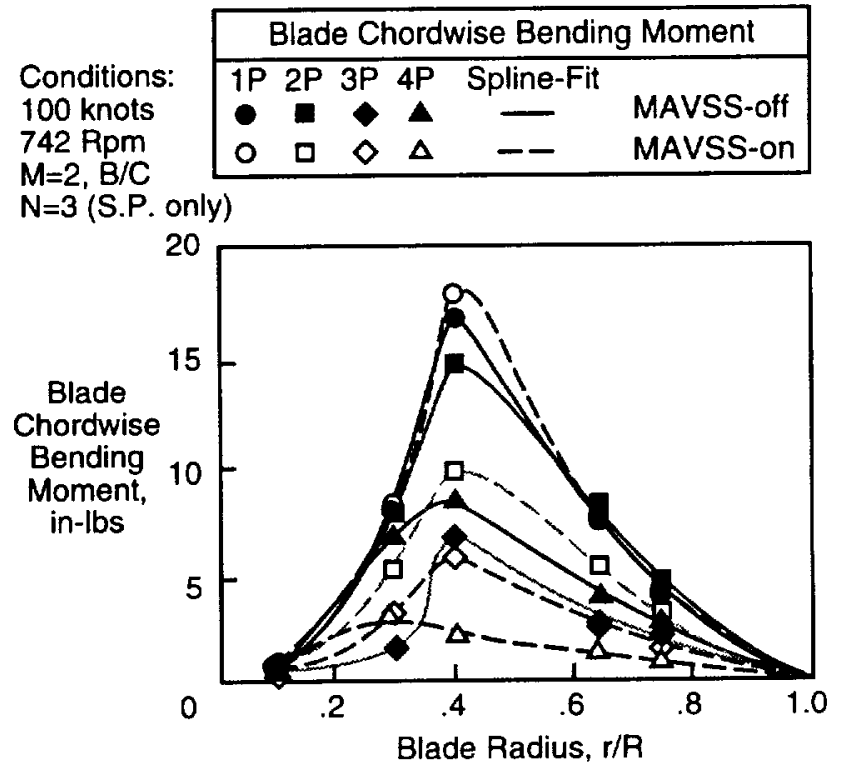

Figure 25. Harmonics of chordwise blade loads associated with combined $1 \mathrm{P} / 3 \mathrm{P}$ performance index. 


\section{Conditions:}

3P-only

742 Rpm

$M=2, B / C$

$N=3$ (S.P. only)
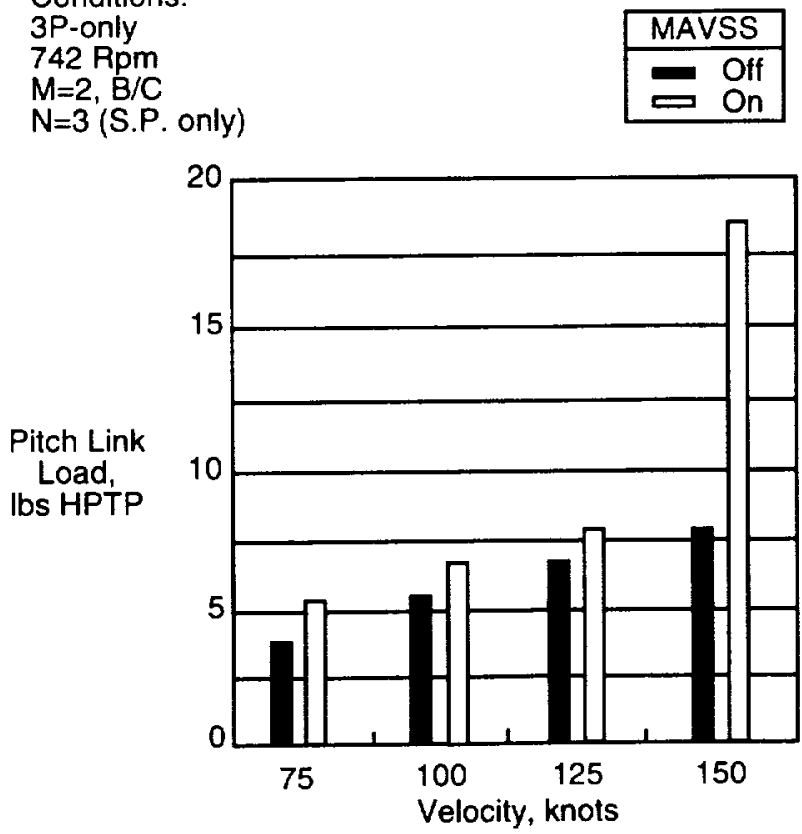

Figure 26. Half-peak-to-peak pitch link loads associated with $3 \mathrm{P}$ performance index.

flapwise bending moment is not reduced by $\mathrm{HHC}$ as much as it had been in the 3P-only case. The harmonics of the chordwise bending moments associated with the $1 \mathrm{P} / 3 \mathrm{P}$ vibration reduction case are shown in Figure [25]. This plot shows that the 2P blade chordwise bending moment is also reduced significantly more than the $2 \mathrm{P}$ blade chordwise bending moment associated with the 3P-only case (Figure [20]). Also, the 3P blade chordwise bending moment is not reduced by $\mathrm{HHC}$ as much as it had been in the $3 \mathrm{P}$-only case.

The reason for the difference in the control system effect on the loads between the 3P-only case and the combined $1 \mathrm{P} / 3 \mathrm{P}$ case is that the MAVSS algorithm gives greater attention to those loads that are the most likely to reduce the performance index. This shifts attention from the $3 \mathrm{P}$ loads in the $3 \mathrm{P}$-only case to the $1 \mathrm{P}$ loads in the 1P/3P case (1P loads are higher for this case than the $3 \mathrm{P}$ loads). With actuators operating at both $1 \mathrm{P}$ and $3 \mathrm{P}$ simultaneously there is going to be a large effect on the $2 \mathrm{P}$ rotating blade loads since the $2 \mathrm{P}$ blade moments are influenced by both the IP and $3 P$ swashplate excitations.

Examples of HHC Effects on Pitch Link Loads. While there is a significant reduction in the vibratory blade bending moments when the HHC system is on, figures [26] and [27] show that, except for the IP harmonic, all the pitch link loads increase. Half-peak-to-peak pitch link loads increase with airspeed and are shown in Figure [26] to always be greater with HHC. In

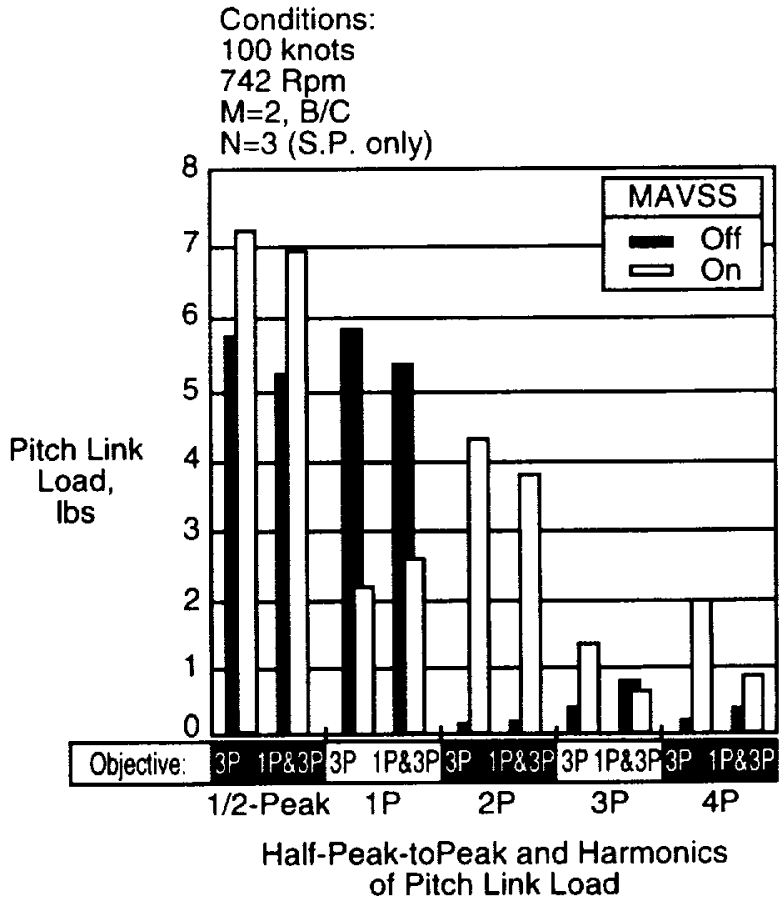

Figure 27. Half-peak-to-peak and harmonics of pitch link loads associated with $3 \mathrm{P}$ and combined $1 \mathrm{P} / 3 \mathrm{P}$ performance indexes.

Figure [27], the half-peak-to-peak loads at a $100 \mathrm{knot}$ airspeed are shown to increase by about 25 and 30 percent for the 3P-only and combined $1 \mathrm{P} / 3 \mathrm{P}$ cases, respectively.

\section{HHC Power Requirements}

The power requirements for the $\mathrm{HHC}$ system installed on the model were estimated for one of the cases tested (3P-only vibration reduction with $N=3$ actuation and $M=3 \mathrm{~B} / \mathrm{C} / \mathrm{T}$ response feedback) using the measured values of the pitch link loads and swashplate amplitudes. The power and the corresponding pitch link loads as a function of tunnel airspeed are shown in Figure [28]. Power is shown as equivalent full-scale horsepower to provide a more intuitive feel for the power requirements associated with this system. Less than 5 horsepower is required for 3 of the 4 velocities considered, but at one velocity (125 knots model scale) power requirements increase to about $13 \mathrm{HP}$ This value corresponds to about $0.2 \%$ of the 6150 SHP available on the V-22 (for each rotor system).

Stroke requirements for the three swashplate actuators corresponding to the case of Figure [28] are shown in Figure [29]. The plot shows that none of the strokes exceed 0.1 inches, and are generally around .05 inches or less for most cases. These values represent less than $5 \%$ of the available stroke of the actuators. 


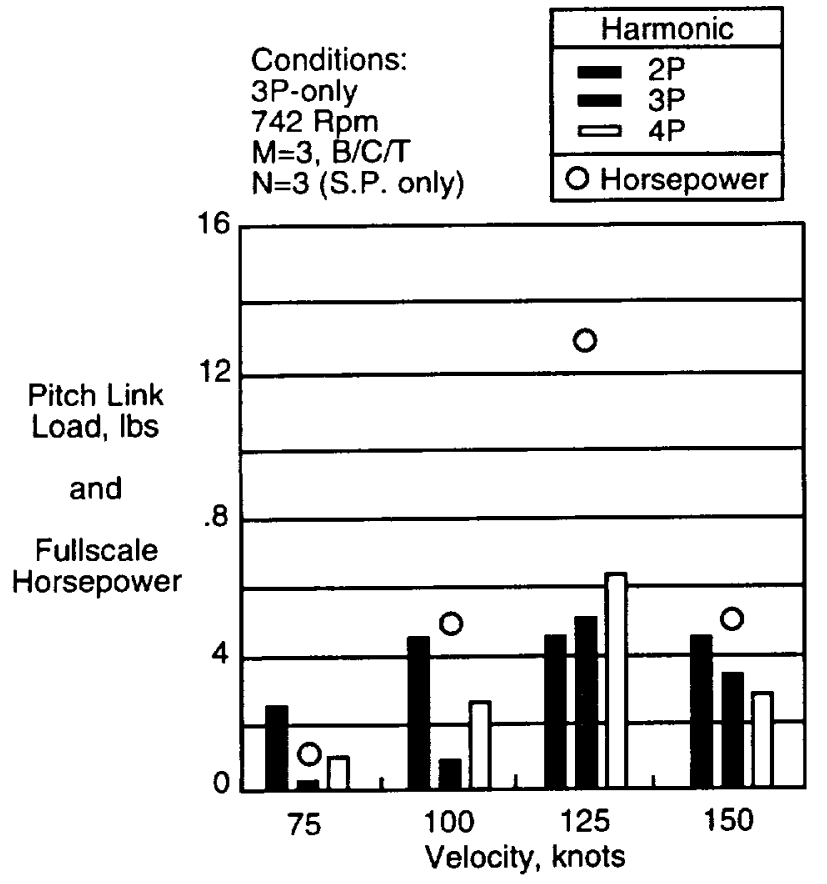

Figure 28. Estimated full-scale horsepower associated with typical $\mathrm{HHC}$ input.

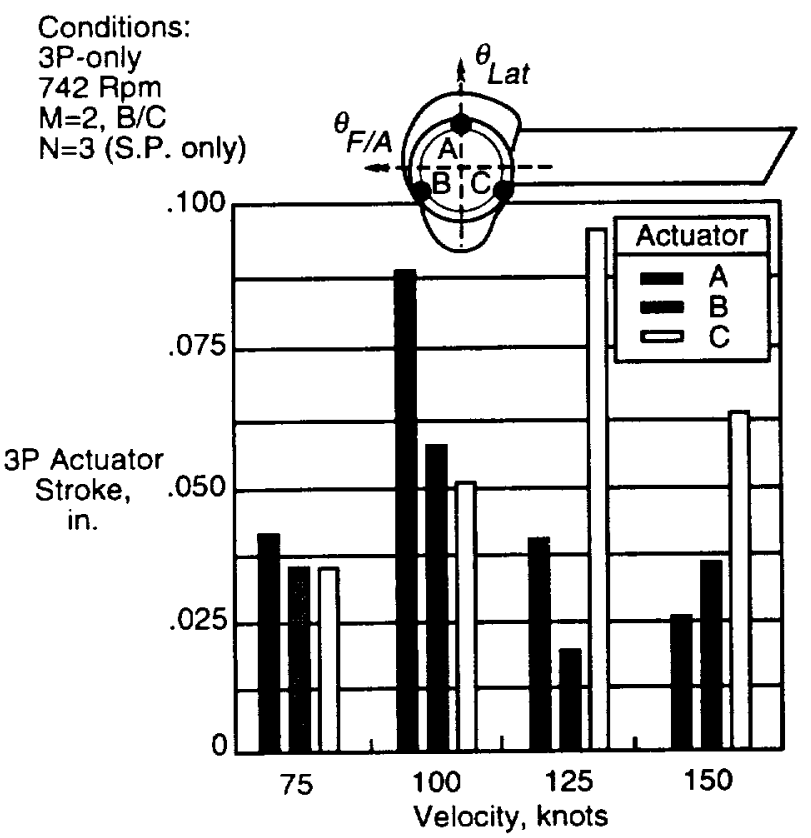

Figure 29. Typical HHC actuator stroke requirements.

\section{CONCLUSIONS}

A joint NASA/Army/Bell Helicopter Textron windtunnel investigation was conducted to assess the potential of higher harmonic control (HHC) for reducing airframe vibrations in tiltrotor aircraft operating in the airplane mode of flight and to evaluate a Bell-developed HHC algorithm for tiltrotor vibration reduction. The studies were made in the Langley Transonic Dynamics Tunnel using an unpowered 1/5scale semispan aeroelastic model of the V-22 modified to incorporate an airframe-based HHC system consisting of both an actively-controlled swashplate and a wing flaperon. The model's 3P vibratory responses resulting from $\mathrm{HHC}$ inputs computed using feedback from pylon accelerometers and wing-root strain gages were measured over a wide range of steady tunnel airspeeds and rotor rotational speeds. Performance of the system was also assessed in transient conditions by rapidly changing tunnel velocity and rotor speed. A limited study of the ability of the control system to suppress 1P vibrations simultaneously with the $3 \mathrm{P}$ vibrations was also made. On the basis of the results shown, the following conclusions are indicated:

1) The HHC system employed was highly effective in reducing vibrations in the wing of the 3-bladed gimballed-rotor model tested. The HHC system was able to consistently reduce the $3 \mathrm{P}$ and $\mathrm{IP}$ vibratory responses, either singly or in combination, by 75-95 percent. The deterministic controller resulting from minimization of a quadratic performance index involving the weighted squares of the vibratory responses and control inputs was found to be adequate for all the wind-tunnel conditions considered.

2) Simultaneous reduction of several independent components of airframe vibration is possible because the effects of different higher harmonic pitch inputs can be superimposed. While the individual vibratory response of any of the three primary wing responses (beam, chord, or torsion) can be significantly reduced using an appropriate single actuator/sensor combination, multiple actuators and sensors must be used to effect the same level of reduction in several independent vibratory components simultaneously. In general, the number of actuators must be equal to or greater than the number of response sensors in order for the $\mathrm{HHC}$ to be effective in reducing multiple vibratory responses.

3) It is known that blade and pitch link oscillatory loads can be increased by HHC. While the vibratory pitch link loads generally increased by 25 percent, the peak vibratory blade bending loads generally decreased by about 25 percent for the model tested.

4) The amplitudes of the higher harmonic pitch angles required to effectively eliminate $3 \mathrm{P}$ vibrations in the 
airframe were modest, generally less than one degree for the swashplate and half a degree for the flaperon. No degradation in aeroelastic stability with respect to the system-off stability characteristics was observed.

5) The HHC system was extremely robust with respect to its performance in the tracking of rapid changes in both the rotor speed and the airspeed, either singly or in combination.

6) The HHC transfer matrix, when identified at a nominal condition, was generally sufficient for a wide range of rotor speeds and tunnel velocities relative to those nominal conditions. Reidentification of the system transfer matrix was rarely required.

7) A gain-scheduled version of the HHC algorithm was found to be almost as effective in reducing vibration as the adaptive version of the algorithm with only a slight advantage in terms of computation time.

8) Despite the considerable differences in dynamic behavior and aerodynamic environment associated with tiltrotors and helicopters, a number of the results obtained in this study are similar to those obtained in studies of HHC for application to helicopters. This indicates that a considerable portion of the existing helicopter HHC technology base may be applicable to tiltrotors.

Based on success of the MAVSS testing conducted on the WRATS $1 / 5$-scale $\mathrm{V}-22$ aeroelastic model in the TDT, BHTI, under sponsorship of the National Rotorcraft Technology Center (NRTC), is preparing for a flight test program of the $\mathrm{XV}-15$ tiltrotor research aircraft using a MAVSS-controlled active elevator. Everything is currently on schedule for a mid-1997 flight test.

\section{REFERENCES}

1. McHugh, F. J., and Shaw, J., "Helicopter Vibration Reduction with Higher Harmonic Blade Pitch," Journal of the American Helicopter Society, Vol. 23, No. 4, October 1978 , pp. 26-35.

2. Wood, E. R., Powers, R. W., and Hammond, C. E., "On Methods for Application of Harmonic Control," Vertica, Vol. 4, pp. 43-60, 1980.

3. Taylor, R. B., Zwicke, P. E., Gold, P., and Miao, W., "Analytical Design and Evaluation of an Active Control System for Helicopter Vibration Reduction and Gust Response Alleviation," NASA CR-152377, July 1980 .

4. Shaw, J., and Albion, N., "Active Control of Rotor Blade Pitch for Vibration Reduction, A Wind Tunnel Demonstration," Vertica, Vol. 4, pp. 3-11, 1980.

5. Molusis, J. A., Hammond, C. E., and Cline, J. H., "A Unified Approach to the Optimal Design of Adaptive and Gain Scheduled Controllers to Achieve Minimum Helicopter Rotor Vibration," Proceedings of the 37th
Annual Forum of the American Helicopter Society, New Orleans, LA, May 17-20, 1981, pp. 188-203.

6. Johnson, W., "Self-Tuning Regulators for Multicyclic Control of Helicopter Vibration," NASA TP 1996, March 1982.

7. Hammond, C.E., "Wind Tunnel Results Showing Rotor Vibratory Loads Reduction Using Higher Harmonic Blade Pitch," Journal of the American Helicopter Society, Vol. 28, No. 1, January 1983, pp. 10-15.

8. Chopra, I., and McCloud, J. L.,III, "A Numerical Simulation Study of Open-Loop, Closed-Loop and Adaptive Multicyclic Control Systems," Journal of the American Helicopter Society, Vol. 28, No. 1, January 1983, pp. 63-77.

9. Davis, M. W., "Refinement and Evaluation of Helicopter Real-Time Self-Adaptive Active Vibration Controller Algorithms," NASA CR 3821, August 1984.

10. Wood, E. R., Powers, R. W., Cline, J. H., and Hammond, C. E., "On Developing and Flight Testing a Higher Harmonic Control System," Journal of the American Helicopter Society, Vol. 30, No. I, January 1985, pp. 3-20.

11. Polychroniadis, M., and Achache, M., "Higher Harmonic Control, "Flight Tests of an Experimental System on SA 349 Research Gazelle," Presented at the 42nd Annual Forum of the American Helicopter Society, Washington, D.C., June 1986.

12. Straub, F. K., and Byrns, E. V., Jr., "Application of Higher Harmonic Blade Feathering on the OH-6A Helicopter for Vibration Reduction," NASA Contractor Report 4031, December 1986.

13. Shaw, J., Albion, N., Hanker, E. J., Jr., and Teal, R. S., "Higher Harmonic Control: Wind Tunnel Demonstration of Fully Effective Vibratory Hub Force Suppression," Journal of the American Helicopter Society, Vol. 34, No. 1, January 1989, pp. 14-25.

14. Hall, S. R., and Wereley, N. M., "Linear Control Issues in the Higher Harmonic Control of Helicopter Vibrations," Proceedings of the 45th Annual Forum of the American Helicopter Society, Boston, MA, May 22-24, 1989, pp. 955-971.

15. Nygren, K. P., and Shrage, D. P., "Fixed-Gain Versus Adaptive Higher Harmonic Control," Journal of the American Helicopter Society, Vol. 34, No. 3, July 1989, pp. 51-58.

16. Nguyan, K. Q., "Higher Harmonic Control Analysis for Vibration Reduction of Helicopter Rotor Systems," University of Maryland Ph.D. Dissertation, UM-AERO89-23, 1989

17. Kretz, M., "Research in Multicyclic and Active Control of Rotary Wings," Vertica, Vol. 1, No. 2, 1976. 
18. McCloud, J. L., III, "The Promise of Multicyclic Control," Vertica, Vol. 4, pp. 29-41, 1980.

19. Ham, N. D., "Helicopter Individual Blade Control and Its Applications," Proceedings of the 39th Annual Forum of the American Helicopter Society, St. Louis, MO, May 9-11, 1983, pp. 613-623.

20. Ham, N. D., "Helicopter Individual-Blade-Control Research at MIT 1977-1985," Vertica, Vol. 11, No. 1/2, 1987, pp. 109-122.

21. Millott, T.; and Friedmann, P., "Vibration Reduction in Helicopter Rotors Using an Active Control Surface Located on the Blade," Proceedings of the 33rd AIAA/ASME/AHS/ASC Structures, Structural Dynamics and Materials Conference, April 13-15, 1992, Dallas, TX, pp. 1975-1988 (AIAA Paper 92-2451CP).

22. Jacklin, S. A.; Nguyen, K. Q.; Blaas, A.; and Richter, P., "Full-Scale Wind Tunnel Test of a Helicopter Individual Blade Control System," Presented at the 50th Annual Forum of the American Helicopter Society, Washington, D.C., May 11-13, 1994.

23. King, S. P.; and Staple, A. E., "Minimization of Helicopter Vibration Through Active Control of Structural Response," Rotorcraft Design for Operations. AGARD CP-423, 1986.

24. Staple, A. E., "An Evaluation of Active Control of Structural Response as a Means of Reducing Helicopter Vibration," Proceedings of the 46th Annual Forum of the American Helicopter Society, Washington, D.C., May 21-23, 1990, Vol. 1, pp. 3-17.

25. Welsh, W. A.; von Hardenberg, P. C.; von Hardenberg, P. W.; and Staple, A. E., "Test and Evaluation of Fuselage Vibration Utilizing Active Control of Structural Response (ACSR) Optimized to ADS-27," Proceedings of the 46th Annual Forum of the American Helicopter Society, Washington, D. C., May 21-23, 1990, pp. 21-37.

26. Welsh, W.; Fredrickson, C.; Rauch, C.; and Lyndon, I., "Flight Test of an Active Vibration Control System on the UH-60 Black Hawk Helicopter," Proceedings of the 51 st Annual Forum of the American Helicopter Society, Fort Worth, TX, May 9-11, 1995, pp. 393-402.

27. Friedmann, P. P., "Rotary-Wing Aeroelasticity with Application to VTOL Vehicles," Proceedings of the 31st AIAA/ASME/ASCE/AHS/ACS Structures,

Structural Dynamics and Materials Conference, Long Beach, CA, April 2-4, 1990, pp. 1624-1670. (AIAA Paper 90-1115-CP).

28. Friedmann, P., "Rotary-Wing Aeroservoelastic Problems," Proceedings of the AIAA Dynamics Specialist Conference, April 16-17, 1992, Dallas, TX, pp. 248-272. (AIAA Paper 92-2107-CP).

29. Frick, J. K.; and Johnson, W., “Optimal Control Theory Investigation of Proprotor/Wing Response to Vertical Gust," NASA TM X-62,384, September 1974.

30. Johnson, W., "Optimal Control Alleviation of Tilting Proprotor Gust Response," NASA TM X62,494 , October 1975 .

31. Whitaker, H. P.; and Cheng, Y., "Use of Active Control Systems to Improve Flapping Responses of a Tilt Rotor VTOL Airplane," MIT ASRL TR 183-1, October 1975.

32. Ham, N. D.; and Whitaker, H. P., "A Wind-Tunnel Investigation of Tilt-Rotor Gust Alleviation Systems," NASA CR-152264, January 1978.

33. Ham, N. D.; Wereley, N. H.; and von Ellenrieder, K D., "Active Control of Gust- and Interference-Induced Vibration of Tilt-Rotor Aircraft," Proceedings of the 45th Annual Forum of the American Helicopter Society, Boston, MA, May 22-24, 1989, pp. 641-653.

34. Settle, T.B.; and Nixon, M.W., "MAVSS Control of an Active Flaperon for Tiltrotor Vibration Reduction," Presented at the 53rd Annual Forum of the American Helicopter Society, Virginia Beach, VA, May 1997.

35. Settle, T. B.; and Kidd, D. L., "Evolution and Test History of the V-22 0.2-Scale Aeroelastic Model," Journal of the American Helicopter Society, Vol. 37, No. 1, January 1992, pp. 31-45.

36. Corso, L.M.; Popelka, D.A.; and Nixon, M.W., "Design, Analysis, and Test of a Composite Tailored Tiltrotor Wing," Presented at the 53rd Annual Forum of the American Helicopter Society, Virginia Beach, VA, May 1997.

37. Schillings, J.; and Reinesch, R, "The Effect of Airframe Aerodynamics on V-22 Rotor Loads," Journal of the American Helicopter Society, Vol. 34, No. 1, January 1989, pp. 26-33. 
